\title{
Emprendimiento colectivo juvenil en clave de Economía Social como una herramienta para la prevención de la violencia
}

Youth collective entrepreneurship based on the Social Economy as a tool for the prevention of violence

\section{Empreendedorismo coletivo juvenil baseado na Economia Social como ferramenta de prevenção à violência}

\section{Carolina Macías de la Torre ${ }^{1}$ Verenice Reyes Cristóbal}

Recibido: 12 de noviembre 2019

Aprobado: 15 de diciembre 2019

Publicado: 13 de enero de 2020

Cómo citar este artículo:

Carolina Macías y Verenice Reyes, Emprendimiento colectivo juvenil en clave de economía social como una herramienta para la prevención de la violencia.

DIXI 31. Enero de 2020, 1-47.

DOI: https://doi.org/10.16925/2357-5891.2020.01.03

Artículo de investigación. https://doi.org/10.16925/2357-5891.2020.01.03

1 Maestría en Innovación Social y Economía Solidaria, Universidad de Salamanca (España). Licenciatura en Ciencias de la Comunicación, Universidad de la Américas, Puebla (México). Vinculada a la Universidad Iberoamericana de Puebla, México.

Correo electrónico: caro_maci@hotmail.com

2 Maestría en Desarrollo Económico y Cooperación Internacional, Benemérita Universidad Autónoma de Puebla (México). Licenciatura en Economía, Benemérita Universidad Autónoma de Puebla.

Correo electrónico verenice.reyes.cristobal@iberopuebla.mx 


\section{Resumen}

Objeto: el presente artículo tiene el propósito de hacer un ejercicio de sistematizar la experiencia de implementación de un programa diseñado para la prevención de las violencias en las juventudes en México, desde el enfoque de la Economía Social. El programa se implementa en diversos estados de la república impulsando emprendimientos colectivos con jóvenes en condiciones de riesgo, a partir de la metodología de acompañamiento e incubación de la Universidad Iberoamericana Puebla. El proyecto tiene como eje central el desarrollo de habilidades para que los jóvenes fortalezcan sus factores de protección ante el riesgo.

Metodología: en este artículo, se describen el objetivo y los fundamentos básicos del proyecto, así como la manera en que se opera desde los diferentes territorios en México, enfatizando en la metodología de acompañamiento utilizada para incubar a los emprendimientos colectivos.

Conclusiones: se concluye presentando la referencia de algunos casos de emprendimientos colectivos acompañados y se finaliza con algunas observaciones que se derivan del acompañamiento que se ha dado a estos colectivos en dos años de trabajo.

Palabras clave: construcción de seguridad ciudadana, emprendimiento colectivo juvenil, jóvenes en riesgo, modelo ecológico para la prevención de las violencias, prevención de violencias.

\section{Abstract}

Objectives: The purpose of this article is to carry out an exercise to systematize the experience of implementing a program designed for the prevention of violence in youth in Mexico, from the perspective of the Social Economy. The program is implemented in various States of the Republic promoting collective undertakings with young people at risk, based on the accompaniment and incubation methodology of the Universidad Iberoamericana Puebla. The central axis of the project is the development of skills for young people to strengthen protective factors against this risk.

Methodology: The objective and basic fundamentals of the project are described in this article, as well as its implementation in the different territories in Mexico, emphasizing the accompanying methodology used to incubate collective undertakings.

Conclusions: It concludes by presenting the reference of some cases of accompanied collective undertakings and ends with some observations derived from the accompaniment that has been given to these groups in two years of work.

Keywords: construction of citizen security, youth collective entrepreneurship, youth at risk, ecological model for the prevention of violence, prevention of violence.

\section{Resumo}

Objetivos: 0 objetivo deste artigo é realizar um exercício de sistematização da experiência de implementação de um programa de prevenção da violência juvenil no México, desde a perspectiva da Economia Social. O programa é executado em vários Estados da República promovendo empreendimentos coletivos com jovens em situação de risco, com base na metodologia de acompanhamento e incubação da Universidad Iberoamericana Puebla. 0 eixo central do projeto é o desenvolvimento de competências para os jovens fortalecerem os fatores de proteção contra este risco.

Metodologia: O objetivo e os fundamentos básicos do projeto são descritos neste artigo, bem como sua implementação nos diferentes territórios do México, enfatizando a metodologia de acompanhamento utilizada para incubar empreendimentos coletivos. 
Conclusões: Conclui apresentando a referência de alguns casos de empreendimentos coletivos acompanhados e termina com algumas observações derivadas do acompanhamento que foi dado a estes grupos em dois anos de trabalho.

Palavras-chave: construção da segurança cidadã, empreendedorismo coletivo juvenil, juventude em situação de risco, modelo ecológico de prevenção da violência, prevenção da violência.

\section{INTRODUCCIÓN}

Es claro observar que, cuando hablamos de los saldos que han resultado de las extremas desigualdades que arroja el modelo económico dominante, salta a la vista la fuerte presencia de condiciones de violencia extrema y ruptura del tejido social en gran parte del mundo. En este contexto, se han impulsado muchos procesos para mitigar estas problemáticas, y compartiendo este objetivo, desde la Universidad Iberoamericana Puebla se buscó la vinculación con aliados para el desarrollo de un programa de Prevención de Violencias y Construcción de Seguridad Ciudadana que abonara a la disminución de las condiciones de violencia que se viven en el país.

El programa de Prevención mencionado comienza su diseño en el 2016 y la implementación se realiza en el 2017 con una duración de tres años, es decir, para la fecha de edición de este artículo, el programa se encuentra aún en operación. Por lo anterior, toda la información presentada en este documento da cuenta de lo realizado a dos años de operación del proyecto.

En general, este artículo busca transmitir al lector los elementos principales sobre los que se diseña el proyecto, las acciones en la implementación, la metodología utilizada, la presentación de algunos casos de incubación y algunas observaciones encontradas a dos años de implementación. Por eso, el límite de este artículo es descriptivo, con la intención de sistematizar una experiencia y presentar algunas observaciones al respecto.

El cuerpo de este documento se estructura de la siguiente manera. Se comienza el primer apartado mencionando los actores clave que participan en el proyecto, partiendo de que la operatividad en cada uno de los territorios se realiza mediante un aliado que, según el territorio, puede ser del sector académico, empresarial o de gobierno.

El segundo apartado presenta la población objetivo del proyecto, enfatizando la focalización específica del programa y en los medios que se han impulsado para llegar a esta población. En el tercer apartado, se describe el modelo de intervención del proyecto, la metodología utilizada y los procesos de seguimiento al emprendimiento 
colectivo, haciendo énfasis en el trabajo de acompañamiento que se realiza con al orientador, figura fundamental en el proyecto.

Se concluye el documento abordando algunas observaciones que se han identificado en el proyecto. Cabe mencionar que este análisis no se presenta desde los resultados de una evaluación de impacto del proyecto; por el contrario, son las observaciones generadas mediante espacios de escucha a los jóvenes que participan en el emprendimiento y a las instituciones que lo respaldan.

\section{CONCEPTUALIZACIÓN}

En respuesta a la globalización que se vive hoy en día, el concepto de seguridad ha recibido diferentes interpretaciones a lo largo de las últimas décadas. Según el Programa de las Naciones Unidas para el Desarrollo (PNUD)', la seguridad ciudadana puede entenderse como una modalidad específica de la seguridad humana (condición de vivir libre de temor y libre de necesidad), relacionada con la seguridad personal y, más específicamente, con amenazas como el delito y la violencia. Dicha concepción está orientada a un enfoque centrado en el bienestar de las personas y considera que este es un requisito indispensable para el desarrollo humano². La seguridad ciudadana se entiende entonces como:

[...] el conjunto de intervenciones realizadas por distintos actores estatales y sociales (gobiernos, sector privado y sociedad civil) a fin de abordary resolver los riesgos y conflictos (reales o previstos) violentos y/o delictivos que son perjudiciales para los derechos y libertades de las personas, a través de la prevención de los mismos. ${ }^{3}$

La seguridad ciudadana, por lo tanto, se considera como un proceso transicional indispensable para hacer frente a la crisis de inseguridad que impera en el país. Se plantea que la participación ciudadana es imprescindible para la convivencia

1 Programa de las Naciones Unidas para el Desarrollo (PNUD). INFORME REGIONAL DE DESARROLLO HUMANO 2013-2014. SEGURIDAD CIUDADANA CON ROSTRO HUMANO: DIAGNÓSTICO Y PROPUESTAS PARA AMÉRICA LATINA. Nueva York: PNUD. (2013).

2 Carolina Macías. Incubación de empresas juveniles de Economía Social, modelo para prevención de violencia y construcción de seguridad ciudadana juvenil Caso: Grupo BSCH. REVISTA IBERO 67. Abril-mayo 2020.

3 Programa de las Naciones Unidas para el Desarrollo (PNUD). INFORME SOBRE DeSARRollo humano 1994. México D.F.: Fondo de Cultura Económica (1994). 
armónica, lo que demanda una actitud proactiva de parte de las personas y las comunidades para entender y dar respuesta y solución a sus necesidades y problemáticas ${ }^{4}$.

En la obra Economía social en contextos de violencia: México y Colombia, de Nadia Castillo ${ }^{5}$, se plantea la pertinencia de la Economía Social para acompañar procesos de pacificación a través de la generación de prácticas de autogestión económica que abonen a la reconstrucción del tejido social y a la resolución pacífica de conflictos en los territorios violentados. Mesa ${ }^{6}$ afirma que existe un cierto consenso global que considera el papel de la sociedad civil como clave en la construcción de procesos de paz; es solo a partir de la suma de esfuerzos y voluntades como se logrará pacificar los territorios.

Castillo ${ }^{7}$ señala que la Economía Social consiste en introducir mayores niveles de trabajo, cooperación y solidaridad en las actividades, organizaciones e instituciones económicas, que permiten generar un conjunto de beneficios sociales y culturales que sobrepasan la esfera del beneficio económico y favorecen a la sociedad en su conjunto, y sobre todo, hace un especial énfasis en el desarrollo del territorio.

Desde el Laboratorio de Innovación Económica y Social (LAINES) de la Universidad Iberoamericana Puebla, se planteó un proyecto que tiene como finalidad hacer un ejercicio de incubación de empresas juveniles bajo el enfoque de Economía Social, cuyo fin último es contribuir a la construcción de seguridad ciudadana juvenil; en lo subsecuente se hará referencia al proyecto como la Plataforma.

Si bien desde el LAINES se han impulsado experiencias de Economía Social en contextos de violencia y de pobreza en diferentes territorios del país, esta vez se eleva la apuesta al implementar el proyecto en seis estados de la república que se destacan por presentar elevados índices de violencia para trabajar específicamente con jóvenes en situación de riesgo.

La visión que se proyecta para la Plataforma es que los jóvenes disfruten de bienestar personal y social y que cuenten con mayores oportunidades socioeconómicas, en condiciones de equidad e igualdad que garanticen su seguridad ciudadana. Si bien se sabe que esta visión es a largo plazo, un objetivo de más fácil alcance es el fortalecimiento de competencias de los jóvenes en los rubros empresarial y social para que desarrollen oportunidades económicas y que, a mediano plazo, esta nueva

4 Carolina Macías, supra, nota 4.

5 Nadia Eslinda Castillo Romero, Coord. EConomía SOCIAL EN CONTEXTOS DE VIOLENCIA: MÉxICo Y COLombIA. Puebla: Universidad Iberoamericana Puebla; Universidad Cooperativa de Colombia. (2018).

Nadia Eslinda Castillo Romero, supra, nota 7. 
condición les permita, de manera directa e indirecta, contribuir a la coproducción de seguridad ciudadana juvenil.

La iniciativa surge como una respuesta a la creciente situación de vulnerabilidad que viven los jóvenes en México debido al desempleo, el rezago educativo y la falta de oportunidades, y como respuesta a la creciente oferta de reclutamiento por parte del crimen organizado y el narcotráfico. Ante este contexto, la propuesta aborda de manera específica dos aspectos: la igualdad de oportunidades económicas para jóvenes y la prevención de la violencia.

Las acciones del programa parten del supuesto de que un cambio social para la prevención y la disminución de las violencias necesariamente exige la reconversión de las relaciones económicas aspirando alcanzar unas más equitativas, democráticas e incluyentes; y exige la promoción de espacios de trabajo digno y una efectiva distribución de la riqueza generada.

El planteamiento, siguiendo la vocación y la razón de ser del LAINES, es trabajar desde la transformación económica para una transformación social. Sin embargo, la relación entre lo económico y lo social se da de manera bilateral de tal forma que se retroalimenta, pues en el ejercicio de incubación si bien el fin último es una transformación económica, las juventudes se van desarrollando en una dimensión social que nutre y fortalece al proyecto empresarial. La hipótesis central de la Plataforma define que:

Si los/las jóvenes realizan sus actividades económicas y laborales en contextos de participación e inclusión, su vulnerabilidad ante las violencias decrece y la Seguridad Ciudadana de sus territorios aumenta. El ámbito central de acción es la generación de oportunidades económicas para ellos/ellas, a través de la transformación de estructuras que propicien su integración en actividades laborales y circuitos económicos que mejoren su ingreso, mantengan espacios de participación y toma de decisiones. ${ }^{8}$

De acuerdo con el PNUD' , los programas de prevención dirigidos a poblaciones de jóvenes en situación de vulnerabilidad deben fomentar la ampliación de sus

8 IBERO Puebla. METOdología PARA EL ACOMPAÑAMIENTO E INCUBACIÓN DE EMPRESAS DE ECONOMÍA SOCIAL. Puebla: Universidad Iberoamericana Puebla. (2017).

9 Programa de las Naciones Unidas para el Desarrollo (PNUD). EMPODÉRATE: JóvENES CREARÁN EMPRESAS SOCIALES EN COMUNIDADES VULNERABLES. Noticias. 8 de febrero de 2019. Disponible en www.mx.undp.org/content/mexico/es/home/presscenter/ articles/2019/02/empoderate---jovenes-crearan-empresas-sociales-en-comunidades-vu.html 
capacidades y oportunidades para alcanzar sus metas a través de medios lícitos. En un contexto de violencia como el que presenta nuestro país, el desarrollo de proyectos de prevención de la violencia juvenil cobra sentido. Según las recomendaciones de la Organización Mundial de la Salud (OMS) ${ }^{10}$, el impulso de estos programas debe incluir:

1. Programas de aptitudes para la vida y el desarrollo social.

2. Programas para la enseñanza de competencias parentales positivas.

3. Enfoques terapéuticos para los jóvenes involucrados.

4. Reducción de acceso al consumo de alcohol.

5. Medidas para reducir el uso nocivo de drogas.

6. Programas de reducción de las concentraciones de pobreza y mejora del entorno urbano.

Se tiene plena conciencia de la multicausalidad y complejidad de la violencia, por lo cual la Plataforma se concibe como una alternativa que si bien no busca resolver el tema de violencia, sí pretende abonar a su prevención y a la construcción de seguridad ciudadana, sumando esfuerzos con muchas otras propuestas y alternativas que desde sus disciplinas y áreas de experiencia aportan a que el problema sea abordado desde diferentes enfoques.

Según la propuesta del LAINES, el elemento innovador en esta búsqueda es el componente económico con el enfoque de Economía Social, cuyos principios y valores cooperativistas promueven el desarrollo de relaciones desde lógicas diferentes a las establecidas por el actual sistema. El desarrollo de capacidades para la creación y consolidación de empresas por parte de jóvenes que no cuentan con alternativas de superación ni de realización los pone en un escenario desde donde pueden proyectar un futuro diferente y más prometedor ${ }^{11}$.

Como parte de todo el proceso de incubación y para el trabajo con las juventudes, se incluyen en el proyecto cuatro enfoques: Seguridad Ciudadana Juvenil, Prevención de las Violencias, Cultura de Paz y Economía Social. Por un lado, se entiende que la Economía Social se expresa en actividades económicas que incluyen principios solidarios, equitativos, justos y democráticos, los mismos que abonarán a la construcción de seguridad ciudadana juvenil mediante la prevención de la violencia y la cultura de paz.

10 Organización Mundial de la Salud (OMS). LA PREVENCIÓN DE LA VIOLENCIA JUVENIL: PANORAMA GENERAL DE LA EVIDENCIA. Washington D.C.: OPS. (2016).

11 Carolina Macías, supra, nota 4. 
La metodología de incubación y acompañamiento diseñada por el LAINES para este proyecto incentiva diferentes actividades con los jóvenes que permiten no solo el desarrollo del modelo y el plan de negocio, sino también una serie de talleres y retos que ponen a los jóvenes como punto de partida de un proceso de transformación que se explicará más adelante. El enfoque de Seguridad Ciudadana Juvenil que se utiliza en la Plataforma considera una ciudadanía juvenil activa y comprometida, coproductora de seguridad por el lugar central que ocupa dentro de la estructura de los emprendimientos que se generan desde la Economía Social ${ }^{12}$.

Tocornal13 afirma que, al igual que la salud, la seguridad es un aspecto fundamental en la calidad de vida, por lo que hoy se habla de "comunidades seguras y vigorosas". Así, la prevención tendría un doble sentido:

1. Atacar los factores que favorecen la criminalidad.

2. Enraizar en la población una actitud o reflejo preventivo dirigido a buscar causas y soluciones frente a esta problemática.

A partir del ejercicio de incubación de empresas de Economía Social promovido entre los jóvenes, se incentiva que mediante ejercicios reflexivos y de toma de conciencia ellos mismos se sitúen en una realidad que les mire como protagonistas no solo de lo que se reduce a su emprendimiento, sino además en un espectro más amplio que abarca el vecindario, el barrio o la comunidad.

Siguiendo con el planteamiento de la Plataforma, la participación y la inclusión son elementos importantes en cuanto a la prevención, ya que a través de esta nueva forma de relacionarse - según lo plantean los principios y valores de la Economía Social- es como se contienen y regulan algunos factores y conductas de riesgo: "La prevención es una herramienta para la contención y regulación de ciertos fenómenos sociales que generan situaciones de riesgo, amenazan la vida cotidiana de las comunidades y vulneran las relaciones de sus habitantes"14.

Cabe aclarar la distinción (tabla 1) entre dos términos asociados cuando se hace referencia al desarrollo de acciones en el marco de la prevención: prevención del delito y prevención de la violencia.

12 Id.

13 Ximena Tocornal. APOYANDo LA PREVEnción EN AmÉRICA LATINA. Santiago: Centro de Estudios en Seguridad Ciudadana. (2004).

14 Fundación Carlos Slim. JUsticıA. s. f. Disponible en https://fundacioncarlosslim.org/ justicia/ 
Tabla 1. Distinción entre prevención del delito y prevención de la violencia

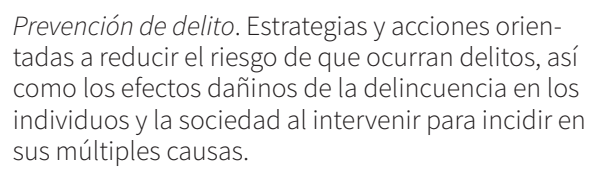
como los efectos dañinos de la delincuencia en los individuos y la sociedad al intervenir para incidir en sus múltiples causas.

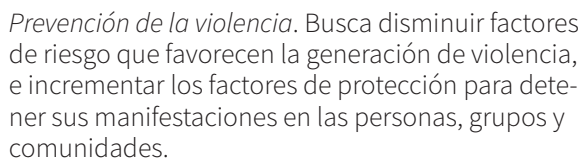

Prevención de la violencia. Busca disminuir factores de riesgo que favorecen la generación de violencia, e incrementar los factores de protección para detener sus manifestaciones en las personas, grupos y comunidades.

Fuente: Información extraída de Fundación Carlos Slim. DIPLOMADO PREVENCIÓN DE LAS VIOLENCIAS Y FoRTALECIMIENTO DE LA SEguRIDAd CIUdAdANA. México D.F.: Fundación Carlos Slim. (2019).

Desde la Plataforma, el término que se busca abordar es la prevención de la violencia iniciando con la disminución de los factores de riesgo y el incremento de los factores de protección de los jóvenes, y con el ejercicio de incubación bajo una metodología diseñada exprofeso para este proyecto. Para ello es fundamental partir de cómo se entiende el riesgo y las condiciones que lo detonan.

Se considera que la población juvenil está en riesgo cuando las circunstancias contextuales y personales dificultan su desarrollo humano e incrementan la probabilidad de desarrollar ciertas problemáticas, como por ejemplo la violencia y la delincuencia. En la Plataforma, se emplea un instrumento de focalización para identificar el nivel de riesgo en el que se encuentran los usuarios. El instrumento mide la exposición y la propensión a la violencia bien como víctima o como victimario.

La violencia juvenil se considera un fenómeno complejo que atraviesa lo relacional, lo psicológico, lo económico, lo político y lo cultural, y que implica la falta de respuestas institucionales que reconozcan que, al ser etapas de transición, tanto la adolescencia como la juventud implican incertidumbre, imprevisibilidad y riesgos ${ }^{15}$. Por lo tanto, algunas de las consecuencias de la violencia asociada con jóvenes son el incremento de homicidios, el consumo excesivo de drogas y alcohol, las grandes cargas financieras sociales a corto y a largo plazo, y la estigmatización de la juventud provocada por la pérdida de confianza y credibilidad en ellas y ellos ${ }^{16}$.

De acuerdo con la Comisión Económica para América Latina y el Caribe (Cepal), la vulnerabilidad alude al resultado de la exposición a riesgos, aunado a la incapacidad para afrontarlos y a la inhabilidad para adaptarse activamente ${ }^{17}$. El hecho de que los jóvenes estén expuestos a la violencia no necesariamente significa que se verán involucrados en ella, por lo que resulta importante contar con un instrumento que identifique, además de la exposición, las variables que podrían detonar conductas violentas, es decir, la propensión.

\footnotetext{
15 Carolina Macías, supra, nota 4.

16 Fundación Carlos Slim, supra, nota 16.

17 Id.
} 
Cuando se habla de la vulnerabilidad como la serie de condiciones socioestructurales que afectan la vida de las personas en determinados contextos, se pueden encontrar algunas clasificaciones que permiten identificar diferentes tipos de vulnerabilidad. La tabla 2 explica dichas dimensiones.

Tabla 2. Dimensiones de la vulnerabilidad

\begin{tabular}{ll}
\hline a. Físico-espacial & $\begin{array}{l}\text { Deterioro de la infraestructura urbana y características físicas que favorecen la violencia y } \\
\text { la delincuencia. }\end{array}$ \\
\hline b. Económica & $\begin{array}{l}\text { Pobreza, desempleo y falta de igualdad de oportunidades que favorecen la ocurrencia de } \\
\text { delitos. }\end{array}$ \\
\hline c. Social & $\begin{array}{l}\text { Desorganización social, falta de redes, desconfianza entre vecinos, presencia de pandillas } \\
\text { o grupos criminales. }\end{array}$ \\
\hline d. Cultural & $\begin{array}{l}\text { Normas y valores que aceptan la violencia como forma de resolver conflictos y obtener } \\
\text { prestigio y actos ilegales como una forma de obtener ingresos. }\end{array}$ \\
\hline
\end{tabular}

Fuente: Información con base en Fundación Carlos Slim. DIPLOMADO PREVENCIÓN DE LAS VIOLENCIAS Y FORTALECIMIENTO DE LA SEguRIDAd CIUdAdANA. México D.F.: Fundación Carlos Slim. (2019)

Al considerar la información presentada en la tabla 2, se puede afirmar que las juventudes con las que se está poniendo en marcha el proyecto efectivamente presentan vulnerabilidad en todas las dimensiones, lo cual se vincula a su propensión y exposición a ejercer violencia, y delimita su condición de riesgo.

Hay una serie de situaciones o condicionantes que incrementan las posibilidades de que una persona sea víctima de violencia o se involucre en hechos violentos; estas situaciones son conocidas como factores de riesgo. El proyecto de la Plataforma, como se ha mencionado, nace de la intención de abonar a la construcción de seguridad ciudadana, partiendo de la premisa de que las condiciones estructurales de desigualdad, entre otras, propician "factores de riesgo" que reproducen la violencia ${ }^{18}$.

De acuerdo con Herrera ${ }^{19}$, los factores de riesgo son variables que pueden alterar negativamente el desarrollo de las personas. Hein ${ }^{20}$ detalla que se refieren a la presencia de situaciones personales o contextuales que incrementan las probabilidades de presentar problemas de salud, emocionales o conductuales, lo que se manifiesta en desajustes que dificultan el desarrollo biopsicosocial de los jóvenes.

La realidad que viven las juventudes no es aislada. Los jóvenes se desarrollan y se relacionan en una red interconectada en la que figuran la familia, la escuela, los

18 Carolina Macías, supra, nota 4.

19 Citado en David Sánchez-Teruel. Factores de riesgo y protección ante la delincuencia en menores y jóvenes. RES: REVISTA DE EDUCACIón SOCIAL 15. Julio 2012. Pág. 1-12.

20 Id. 
grupos de pares y otras instituciones que tienen influencia directa o indirecta en sus vidas y que pueden convertirse en factores de riesgo o de protección²1.

Cabe hacer la distinción entre dos conceptos que no son lo mismo; "los factores de riesgo son situaciones o características que disminuyen la probabilidad de lograr un desarrollo pleno, mientras que el término conducta de riesgo se refiere al resultado sobre el comportamiento humano que tienen dichos factores"22.

En la tabla 3, se presentan las clasificaciones de los factores y las conductas de riesgo; los factores están relacionados con los ámbitos de procedencia. Vale la pena mencionar que durante la etapa juvenil, y como parte del desarrollo mismo, las conductas de riesgo tienen un carácter experimental que en algunos casos cesarán con el tiempo, pero que en otros persistirán e incluso se agravarán ${ }^{23}$.

Tabla 3. Relación entre factores de riesgo y conductas de riesgo

\begin{tabular}{ll}
\multicolumn{1}{c}{$\begin{array}{c}\text { Factores de riesgo. Trudel } \\
\text { y Puentes Neuman }{ }^{24}\end{array}$} & Conductas de riesgo. Hein ${ }^{25}$ \\
\hline Factores individuales & Abuso de tóxicos \\
Factores familiares & Relaciones sexuales no protegidas \\
Factores ligados al grupo de iguales & Bajo rendimiento, fracaso o absentismo escolar \\
Factores escolares & Delincuencia, crimen o violencia \\
Factores sociales o comunitarios & \\
Factores socioeconómicos y culturales & \\
\hline
\end{tabular}

Fuente: Elaboración propia con base en Fundación Carlos Slim. DIPLOMADO PREVENCIÓN DE LAS VIOLENCIAS Y FORTALECIMIENTO DE LA SEGURIDAD CIUDADANA. México D.F.: Fundación Carlos Slim. (2019)

Para el proyecto de la Plataforma, se retoma el análisis desde los factores de riesgo. En la tabla 4, se presentan estos factores que contribuyen a reproducir o a aumentar la violencia, en el entendido de que la violencia es el producto de una serie de factores, características o situaciones que rodean a una persona o a grupos de personas en un espacio determinado, y que aumentan la probabilidad de desarrollar problemas de conducta o comportamientos de agresividad.

21 David Sánchez-Teruel. Factores de riesgo y protección ante la delincuencia en menores y jóvenes. RES: REVISTA DE EDUCACIÓN SOCIAL 15. Julio 2012. Pág. 1-12.

22 Id.

23 Id.

24 Citado en David Sánchez-Teruel, supra, nota 23.

25 Id. 
Tabla 4. Factores de riesgo que incrementan la violencia

\begin{tabular}{ll}
\hline \multicolumn{1}{c}{$\begin{array}{c}\text { Situación de } \\
\text { vulnerabilidad }\end{array}$} & \multicolumn{1}{c}{ Factores de riesgo } \\
\hline Individual & - Consumo de alcohol y drogas \\
& Precariedad educativa \\
& Algunos problemas de salud mental \\
& - Dificultades para la inserción laboral \\
\hline Socio-espacial & Discriminación socioespacial (por el lugar donde se vive) \\
& - Marginación \\
& - Acceso desigual a servicios públicos e infraestructura básica \\
\hline Estructural & Participación ciudadana debilitada y falta de cohesión social \\
& - Acceso desigual a la seguridad social y a las oportunidades laborales \\
& Desigualdad de ingresos \\
& Exclusión social \\
\hline & Desconfianza en las instituciones y en las demás personas \\
\hline
\end{tabular}

Fuente: Fundación Carlos Slim. DIPLOMADO PREVENCIÓN DE LAS VIOLENCIAS Y FORTALECIMIENTO DE LA SEGURIDAd CIUdAdANA. México D.F.: Fundación Carlos Slim. (2019)

Sumado a lo anterior y detallando los factores de riesgo, Interpeace y Poljuve26 señalan que entre esta clase de factores se encuentran: la violencia intrafamiliar, la deserción escolar o la violencia en las escuelas, el desempleo o el subempleo, crecer en entornos de alta conflictividad y violencia, el fácil acceso a drogas y armas de fuego, migrar en condiciones precarias, la desigualdad social, la exclusión, la falta de oportunidades y, en general, la marginación e inatención social a los más vulnerables.

Otro elemento que fomenta el riesgo, según información de la Asamblea General de Naciones Unidas ${ }^{27}$, es la estigmatización juvenil; en la opinión predominante de los expertos, calificar a un joven de "extraviado", "delincuente" o "predelincuente" a menudo contribuye a que los jóvenes desarrollen pautas permanentes de comportamiento indeseable.

Con el análisis de los factores de riesgo, se han generado muchas propuestas de intervención en materia de prevención, muchas de ellas construidas desde el modelo ecológico, ya que permite entender y explicar la complejidad del fenómeno de la violencia. Es un modelo que se basa en la teoría de sistemas y que tiene dos principios fundamentales (modelo ecológico de Bonfenbrenner ${ }^{28}$ ):

26 Citados en IBERo Puebla, supra, nota 10.

27 Asamblea General de la Organización de Naciones Unidas. DIRECTRICES DE RIAD. ONU. (1990).

28 Francisco Castellanos García. CONSTRUYENDo MODELOS DE INTERVENCIÓN CON JóVENES. México D.F.: Programa para la Convivencia Ciudadana USAID. (2015). 
1. Que el ser humano es dinámico y que está en constante desarrollo.

2. Que toda persona se desarrolla en un entorno cambiante en el que las relaciones, las personas, los entornos y los contextos se afectan multidireccionalmente y se modifican constantemente unos a otros.

El modelo ecológico entiende "la violencia no solo desde un enfoque de víctimas y victimarios, sino como la interacción de las personas en diferentes niveles y contextos mediante el análisis de sus características individuales, relaciones cercanas, vínculos comunitarios e inserción social"29. Desde este enfoque, se destacan las diferentes causas y su relación con los factores de riesgo y de protección que operan en los niveles individual, relacional, comunitario y social. Se afirma que los factores de riesgo interactúan de forma compleja en cada nivel, lo que reduce o aumenta la vulnerabilidad de las personas frente a la violencia ${ }^{30}$. En la tabla 5 , se asocian los factores de riesgo y de protección con los niveles que componen el modelo ecológico:

Tabla 5. Descripción de los elementos abordados por el enfoque ecológico asociado a factores de riesgo y de protección

\begin{tabular}{|c|c|c|}
\hline \multirow[t]{2}{*}{ Individual } & Factor riesgo & $\begin{array}{l}\text { Características del individuo que aumentan la probabilidad de ser } \\
\text { víctima o victimario de actos de violencia. Busca identificar factores } \\
\text { biológicos y la historia personal que influyen en el comportamiento } \\
\text { de una persona, considera otros factores como la impulsividad, el } \\
\text { abuso de sustancias psicoactivas y antecedentes de haber sufrido } \\
\text { maltrato o de comportamiento agresivo. }\end{array}$ \\
\hline & Factor protección & $\begin{array}{l}\text { Reconocimiento de aptitudes individuales, autoestima positiva, } \\
\text { resolución positiva de conflictos, etc. }\end{array}$ \\
\hline \multirow[t]{2}{*}{ Relacional/Familiar } & Factor riesgo & $\begin{array}{l}\text { Explora cómo en las relaciones cercanas (amigos, pareja, familia) } \\
\text { pueden incrementar las probabilidades de ser víctima o perpetra- } \\
\text { dor de actos violentos. }\end{array}$ \\
\hline & Factor protección & $\begin{array}{l}\text { Crianza positiva, familias democráticas, cohesión familiar, ambien- } \\
\text { tes escolares pacíficos, etc. }\end{array}$ \\
\hline \multirow[t]{2}{*}{ Comunitario } & Factor riesgo & $\begin{array}{l}\text { Examina los contextos en los que se dan las relaciones socia- } \\
\text { les como la escuela, el lugar de trabajo y el vecindario, y cómo } \\
\text { aspectos de estos ámbitos pueden propiciar que una persona sea } \\
\text { víctima o perpetradora de actos violentos. Escasa o nula cohesión } \\
\text { social, desempleo, alta densidad poblacional, tráfico de drogas, } \\
\text { desconfianza en las instituciones y aislamiento social generalizado } \\
\text { son factores que incrementan la probabilidad de que se presenten } \\
\text { hechos violentos. }\end{array}$ \\
\hline & Factor protección & $\begin{array}{l}\text { Lazos de vecindad, mejora de colonias y barrios, participación } \\
\text { ciudadana, disminución y control al acceso de armas de fuego, } \\
\text { drogas, alcohol, etc. }\end{array}$ \\
\hline
\end{tabular}


(viene)

\begin{tabular}{ll}
\hline & $\begin{array}{l}\text { Normas culturales que legitiman la violencia, normas que refuerzan } \\
\text { el dominio masculino sobre mujeres y niños, normas que avalan } \\
\text { uso excesivo de la fuerza policial en contra de los ciudadanos, } \\
\text { nocial }\end{array}$ \\
& $\begin{array}{l}\text { Políticas que apoyan conflictos políticos. } \\
\text { mantienen niveles altos de desigualdad económica y social entre } \\
\text { diferentes grupos de la sociedad. }\end{array}$ \\
\hline \multirow{2}{*}{ Factor protección } & $\begin{array}{l}\text { Cultura de legalidad, publicidad responsable, mejores espacios y } \\
\text { servicios públicos, etc. }\end{array}$ \\
\hline
\end{tabular}

Fuente: Elaboración propia a partir de información obtenida de Fundación Carlos Slim. DIPLOMADO PREVENCIÓN DE LAS VIOLENCIAS Y FORTALECIMIENTO DE LA SEGURIDAD CIUDADANA. México D.F.: Fundación Carlos Slim. (2019)

Por su parte, el estudio "Predictores de la conducta antisocial juvenil: un modelo ecológico"31, de Martha Frías, Amelia López y Sylvia Díaz, concluye que el modelo ecológico de Bronfenbrenner constituye una representación adecuada de la generación y el mantenimiento de la conducta antisocial juvenil. En el estudio, se asocian algunas variables que se consideran factores predictores con los distintos niveles del modelo ecológico y se encontró que sí se relacionan. Algunos hallazgos del estudio se presentan en la tabla 6:

Tabla 6. Factores precursores de la violencia juvenil

\section{Factores precursores de la conducta antisocial juvenil}

- Si desde la infancia presenta conductas antisociales (golpear, robar o causar daños en bienes ajenos).

- Si los padres ejercen violencia física o emocional hacia los hijos.

- Si existe violencia entre la pareja.

- Cuando hay mayor frecuencia y cantidad en el consumo de alcohol o drogas por parte de los padres.

- Si existe una percepción negativa del ambiente familiar.

- La percepción de que el barrio es peligroso e inseguro. El descuido, la venta de alcohol, infraestructura inadecuada y deficiente que facilite la comisión de delitos.

- Si el ambiente es hostil o existen conductas inapropiadas en la escuela.

- Si existen actitudes negativas toleradas por los jóvenes como mentir, robar, evadir la justicia, no respetar reglas, actuar de forma imprudente y arriesgada.

Fuente: Elaboración propia con base en Francisco Castellanos García. CONSTRUYENDO MODELOS DE INTERVENCIÓN CON JóvENES. México D.F.: Programa para la Convivencia Ciudadana USAID. (2015).

\section{Sistema de referencia}

Entorno individual

Entorno relacional

Entorno comunitario

Entorno social

31 Citados en Francisco Castellanos García, supra, nota 30 
En la tabla 7, se presentan algunos de los factores de riesgo que no están asociados exclusivamente con los jóvenes, pero que se encuentran en el sistema y que detonan otros tipos de violencias, lo que eventualmente repercute en sus vidas.

Tabla 7. Factores de riesgo que incrementan la violencia con base en el modelo ecológico

\begin{tabular}{|c|c|c|c|}
\hline \multicolumn{4}{|c|}{ Factores de riesgo para la violencia basado en el modelo ecológico } \\
\hline Social & Comunitario & Relacional & Individual \\
\hline $\begin{array}{l}\text { Factores amplios que } \\
\text { reducen las inhabilidades } \\
\text { contra la violencia }\end{array}$ & $\begin{array}{l}\text { Vecindario, escuela, lugar } \\
\text { de trabajo }\end{array}$ & $\begin{array}{l}\text { Con la familia, pareja y } \\
\text { amigos }\end{array}$ & $\begin{array}{l}\text { Factores personales que } \\
\text { influencian el comporta- } \\
\text { miento individual }\end{array}$ \\
\hline \multirow{3}{*}{$\begin{array}{l}\text { - Pobreza } \\
\text { - Inequidad económica, } \\
\text { social y de género }\end{array}$} & - Alto nivel de desempleo & - Disfunción familiar & \multirow{2}{*}{$\begin{array}{l}\text { - Edad, género y edu- } \\
\text { cación }\end{array}$} \\
\hline & \multirow{2}{*}{$\begin{array}{l}\text { - Alta densidad pobla- } \\
\text { cional }\end{array}$} & \multirow{3}{*}{$\begin{array}{l}\text { - Violencia intergenera- } \\
\text { cional, malas prácticas } \\
\text { parentales }\end{array}$} & \\
\hline & & & - Historia familiar de \\
\hline - Escasa seguridad social & \multirow{2}{*}{$\begin{array}{l}\text { - Aislamiento social de } \\
\text { las mujeres y la familia }\end{array}$} & & \\
\hline - Masculinidad vinculada & & \multirow{2}{*}{$\begin{array}{l}\text { - Conflicto parental que } \\
\text { involucra violencia }\end{array}$} & \multirow{2}{*}{$\begin{array}{l}\text { - Víctima de abuso infan- } \\
\text { til o negligencia }\end{array}$} \\
\hline a agresión y dominio & - Falta de información & & \\
\hline $\begin{array}{l}\text { - Débil sistema de justicia } \\
\text { legal y criminal }\end{array}$ & $\begin{array}{l}\text { - Cuidados inadecuados } \\
\text { a víctimas }\end{array}$ & \multirow{2}{*}{$\begin{array}{l}\text { - Asociación con amis- } \\
\text { tades que participan } \\
\text { en comportamientos } \\
\text { violentos y delincuentes }\end{array}$} & $\begin{array}{l}\text { - Presenciar violencia de } \\
\text { género }\end{array}$ \\
\hline \multirow{2}{*}{$\begin{array}{l}\text { - Perpetradores no pro- } \\
\text { cesados }\end{array}$} & \multirow{2}{*}{$\begin{array}{l}\text { - Sanciones débiles } \\
\text { comunitarias }\end{array}$} & & \multirow{2}{*}{$\begin{array}{l}\text { - Falta de sustento y de } \\
\text { ingresos personales } \\
\text { suficientes }\end{array}$} \\
\hline & & \multirow{2}{*}{$\begin{array}{l}\text { - Bajo nivel socioeconó- } \\
\text { mico o estrés socioeco- } \\
\text { nómico }\end{array}$} & \\
\hline $\begin{array}{l}\text { - Falta de derechos lega- } \\
\text { les para las víctimas }\end{array}$ & $\begin{array}{l}\text { - Escasa seguridad en } \\
\text { espacios públicos }\end{array}$ & & - Desempleo \\
\hline \multirow{2}{*}{$\begin{array}{l}\text { - Normas sociales y } \\
\text { culturales que apoyan } \\
\text { la violencia }\end{array}$} & - Culpar a las víctimas & \multirow{3}{*}{$\begin{array}{l}\text { - Fricción sobre el } \\
\text { empoderamiento de las } \\
\text { mujeres }\end{array}$} & \multirow{2}{*}{$\begin{array}{l}\text { - Salud mental y pro- } \\
\text { blemas de comporta- } \\
\text { miento }\end{array}$} \\
\hline & \multirow{6}{*}{$\begin{array}{l}\text { - Violación de la con- } \\
\text { fidencialidad de las } \\
\text { víctimas }\end{array}$} & & \\
\hline $\begin{array}{l}\text { - Armas de fuego pe- } \\
\text { queñas }\end{array}$ & & & $\begin{array}{l}\text { - Abuso de alcohol y } \\
\text { sustancias }\end{array}$ \\
\hline - Conflicto o posconflicto & & & - Prostitución \\
\hline - Desplazamiento interno & & & $\begin{array}{l}\text { - Refugiados desplazados } \\
\text { internamente }\end{array}$ \\
\hline \multirow[t]{2}{*}{ - Refugiados } & & & - Discapacidades \\
\hline & & & $\begin{array}{l}\text { - Propiedad de armas de } \\
\text { fuego pequeñas }\end{array}$ \\
\hline
\end{tabular}

Fuente: Elaboración propia con base en onU Mujeres. MARCO ECOLÓGICO. 2013. Disponible en https:// www.endvawnow.org/es/articles/1509-marco-ecolgico.html

De la misma forma en que se categorizan los factores que ponen en riesgo al joven ante la violencia, se presentan también los factores de protección, entendidos como las condiciones existentes o aquellas generadas intencionalmente con la finalidad de contrarrestar las situaciones adversas que se les presentan a los jóvenes, con lo que se les permite superar situaciones de riesgo y el desarrollo de la resiliencia ${ }^{32}$.

32 Francisco Castellanos García, supra, nota 30. 
Los factores de protección se encuentran en el entorno, pero también en las habilidades que desarrollan las personas, las familias y los grupos sociales. La Plataforma plantea que a partir del desarrollo de ciertas capacidades se dota a los jóvenes de factores de protección, esencialmente en dos ámbitos del modelo ecológico: el individual y el relacional.

Tabla 8. Factores de protección

\begin{tabular}{|c|c|c|c|}
\hline Individuales & Familia & Escuela & Comunidad \\
\hline \multirow{3}{*}{$\begin{array}{l}\text { - Atributos personales } \\
\text { (temperamento fácil, } \\
\text { autonomía, competen- } \\
\text { cias sociales) }\end{array}$} & - Amor, apego familiar & \multirow{2}{*}{$\begin{array}{l}\text { - Relaciones positivas } \\
\text { con profesores }\end{array}$} & \multirow{2}{*}{$\begin{array}{l}\text { - Redes de apoyo y pro- } \\
\text { tección }\end{array}$} \\
\hline & \multirow{2}{*}{$\begin{array}{l}\text { - Apoyo maternal y } \\
\text { emocional }\end{array}$} & & \\
\hline & & - Apoyo integral y afectivo & - Pares que apoyan \\
\hline $\begin{array}{l}\text { - Facilidad para resolver } \\
\text { conflictos pacífica- } \\
\text { mente }\end{array}$ & $\begin{array}{l}\text { - Prácticas parentales } \\
\text { (coherentes, expectati- } \\
\text { vas positivas) }\end{array}$ & \multirow[t]{2}{*}{$\begin{array}{l}\text { - Clima social escolar } \\
\text { centrado en los estu- } \\
\text { diantes, colaboradory } \\
\text { seguro }\end{array}$} & \multirow[t]{5}{*}{$\begin{array}{l}\text { - Deportes, clubes } \\
\text { (promueven identidad } \\
\text { positiva, sentido de } \\
\text { pertenencia) }\end{array}$} \\
\hline - Alta autoestima & \multirow{4}{*}{$\begin{array}{l}\text { - Modelo de resiliencia } \\
\text { (padres, hermanos) }\end{array}$} & & \\
\hline - Autoeficiencia & & $\begin{array}{l}\text { - Currículo relevante y } \\
\text { adecuado a la edad }\end{array}$ & \\
\hline - Sentido de propósito & & \multirow{2}{*}{$\begin{array}{l}\text { - Programas de apoyo } \\
\text { especiales }\end{array}$} & \\
\hline - Actitud positiva & & & \\
\hline
\end{tabular}

Fuente: Información obtenida de Fundación Carlos Slim. DIPLOMADO PREVENCIÓN DE LAS VIOLENCIAS Y FORTALECIMIENTO dE LA SEguRIDAd CIUdAdANA. México D.F.: Fundación Carlos Slim. (2019).

De acuerdo con Castellanos ${ }^{33}$, las estrategias de prevención deben considerar:

1. Fortalecer factores de protección.

2. Dirigirse a los jóvenes en general o al grupo específico según el nivel que se quiera abordar.

3. Focalizarse en un contexto comunitario.

Al hacer una observación de las condiciones de riesgo para los jóvenes, una de las más concurrentes en nuestro país tiene que ver con los factores de exposición, presentes en un contexto de extrema inseguridad, violencia y desigualdad. Los principales hallazgos del informe que presenta el Índice de Paz México (IEP) ${ }^{34}$ señalan que, ante la escalada de violencia, el Gobierno ha invertido en el sistema judicial menos de lo que se requiere.

A pesar de que se reportó que en el 2018 el índice de paz se deterioró en 4,8\% y que la tasa de homicidios se incrementó en $18 \%$, el gasto del Gobierno en las fuerzas policiales y el sistema judicial como porcentaje del Producto Interno Bruto (PIB)

33 Francisco Castellanos García, supra, nota 30.

34 The Institute for Economics and Peace (IEP). ÍNDICE DE PAZ MÉXICO 2019: IDENTIFICAR Y MEDIR LoS FACTORES QUE IMPULSAN LA PAZ. México D.F.: IEP. (2019). 
es apenas la mitad del promedio de los demás países que integran la Organización para la Cooperación y el Desarrollo Económicos (OCDE). Aunado a ello, únicamente en $7 \%$ de los delitos se abrieron carpetas de investigación en el 2017 y menos de $3 \%$ terminaron en una sentencia, lo que arrojó una tasa de impunidad de $97 \%$.

El impacto económico de la violencia se elevó $10 \%$ en el 2018, alcanzando los 5,16 billones de pesos (268 000 millones de dólares), lo que equivale a $24 \%$ del PIB del país. En términos per cápita, el impacto económico de la violencia fue de 41181 pesos, más de cinco veces el salario mensual promedio de un trabajador mexicano. La calificación de distribución equitativa de los recursos registró el mayor retroceso de todos los pilares, al bajar 12,3\% del 2005 al 201735. Estas son algunas de las cifras que reflejan parte de la problemática que se presenta en el país.

Entre los estados menos pacíficos, reportados por el Institute for Economics and Peace ${ }^{36}$, encabezando la lista de los cinco menos pacíficos se encuentra Baja California en el primer lugar y también aparece Chihuahua; ambos pertenecen a los territorios donde se implementa la Plataforma.

Cabe destacar también que el informe mencionado aborda la panorámica de la paz positiva: "Una Paz Positiva bien desarrollada representa la capacidad de una sociedad para cubrir las necesidades de sus ciudadanos, disminuir los agravios que surjan y solucionar los demás desacuerdos sin usar la violencia"37. Se ha comprobado que los procesos de reconstrucción de paz exitosos implican un abordaje desde diferentes y múltiples acciones sostenidas en el tiempo y de manera simultánea. Se contemplan mejoras en toda la sociedad. En este orden de pensamiento, la Plataforma pretende ser un esfuerzo más en esta suma de acciones necesarias para reinstaurar la paz en el país. El IEP plantea que existen ocho pilares de la paz positiva ${ }^{38}$ :

- Buen funcionamiento del Gobierno

- Distribución equitativa de los recursos

- Libre flujo de información

- Entorno empresarial sólido

- Alto nivel de capital humano

- Aceptación de los derechos de los demás

- Bajos niveles de corrupción

- Buenas relaciones con los vecinos

35 Id.

$36 I d$.

37 Id.

38 Id. 
Sostener la paz implica más que limitarse a atender los factores que provocan la violencia; se requiere que México combine la aplicación efectiva de la ley a corto plazo y que sostenga avances en paz positiva a largo plazo ${ }^{39}$. En términos de paz positiva, se intuye que la Plataforma contribuirá a largo plazo en la distribución equitativa de los recursos al seguir los principios y valores de la Economía Social en la conformación de los emprendimientos colectivos juveniles. Así mismo, se prevé que los jóvenes incrementen sus capacidades y por lo tanto sus competencias sociales y empresariales, lo que fortalece el capital humano al brindarles una oportunidad de formación y de empleo. En un futuro más lejano, y con la consolidación de los emprendimientos y la conformación de otros nuevos, se podría aportar al entorno empresarial que en esta fase del proyecto ha sido un factor clave en algunos de los territorios.

Como se ha podido comprobar en los territorios del norte de México, el IEP40 señala que nuestro país muestra como fortaleza un entorno empresarial sólido; esto ha permitido, en el estado de Chihuahua específicamente, impulsar el proceso de la Plataforma. Por otro lado, se observan los otros tres pilares presentados como fortalezas para nuestro país: altos niveles de capital humano, aceptación de los derechos de los demás y buenas relaciones con los vecinos. Se afirma que la cooperación de la comunidad sigue mejorando, ya que la proporción de mexicanos que dicen que su comunidad se organiza para resolver problemas ha aumentado diez puntos porcentuales desde el 2012; esta es una oportunidad para difundir los principios del cooperativismo, ya que sí se ha percibido que los jóvenes, sobre todo en contextos más urbanos, carecen de apertura para generar confianza en los otros y emprender en colectivo.

En términos de la Plataforma, se hizo un diseño que contempla el fortalecimiento de factores de protección a partir de la implementación de una ruta del emprendimiento para la incubación de empresas de Economía Social, la cual se mencionará con más detalle en apartados siguientes.

Para el impulso de acciones que abonen a los factores de protección en el país, la Plataforma decide implementar un proceso de intervención para detonar o fortalecer algunos factores, seleccionando contextos en la república donde el riesgo está muy presente. Los territorios que se escogen para trabajar abarcan cinco estados de la República Mexicana: Baja California, Chihuahua, Jalisco, Estado de México y Michoacán. El proyecto en estos territorios se implementó según sus condiciones y características; sin embargo, hay elementos básicos que se presentan en todos ellos:

39 Id.

40 Id. 
1. La organización con aliados clave.

2. La focalización de la población.

3. La aplicación de un modelo común de acompañamiento y seguimiento.

\section{Aliados clave}

La complejidad del proyecto, con una participación nacional, demanda la articulación de aliados con presencia y trabajo previo de intervención en los territorios. Para ello, en la Plataforma se desarrolla un modelo vinculado de trabajo desde diferentes niveles de intervención, como se muestra en la figura 1.

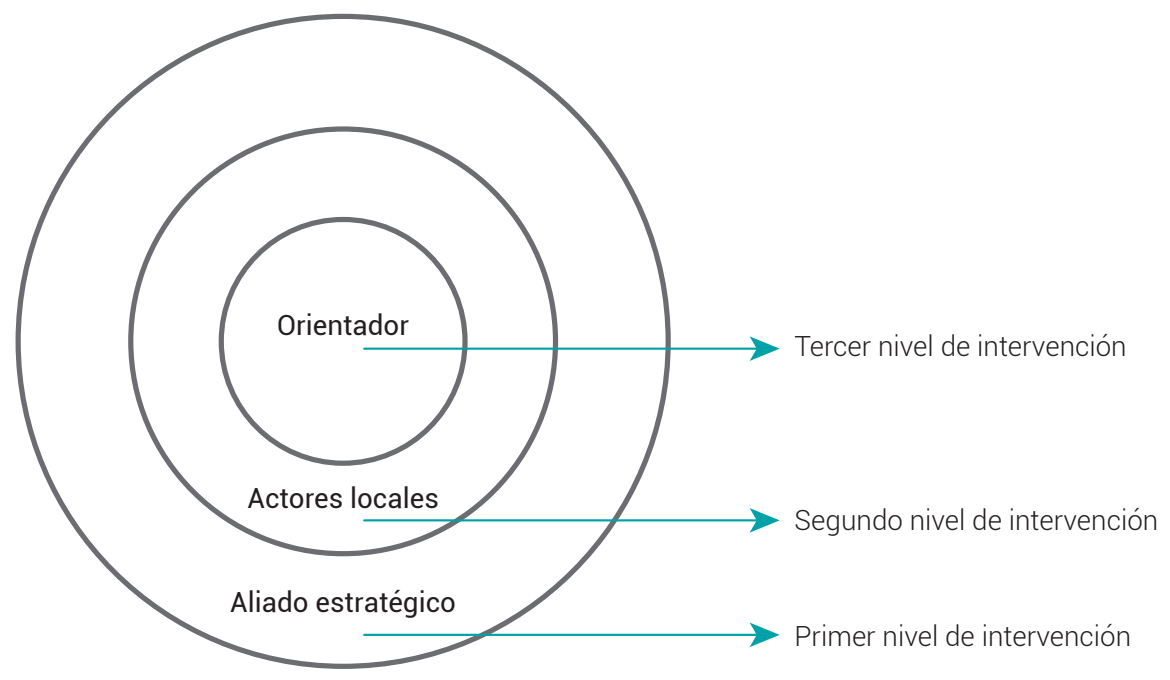

Figura 1. Descripción de aliados clave

Fuente: Elaboración propia con base en LAINES $^{41}$

a) Primer nivel: Corresponde al diálogo institucional que se crea con un aliado estratégico en los territorios, que es quien implementa y coordina el proyecto. Este aliado asume la operatividad y da el respaldo institucional para que dicho proyecto opere con éxito.

b) Segundo nivel: La articulación de redes de apoyo que sostengan el proyecto es fundamental; el aliado estratégico y las figuras operativas del proyecto vinculan e impulsan la búsqueda de aliados locales que den fortalecimiento a los emprendimientos colectivos acompañados. Es indispensable que actores locales intervengan aportando el acceso a los recursos que tienen

41 Laboratorio de Innovación Económica y Social (LAINES). REPORTE ANUAL PCSCJM 2019. Puebla: LAINES. (2019). 
a su disposición. Un ejemplo común en este proceso es el aporte de instituciones que cuentan con capacidad técnica para fortalecer el modelo de negocio, ofreciendo espacios para que los colectivos desarrollen una marca, una imagen corporativa, profesionalicen su producto, etc. En este nivel, es importante el trabajo con instituciones que tengan experiencia en la población objetivo: centros de rehabilitación para el uso de sustancias adictivas, centros de internamiento y Centros de Readaptación Social (CE. RE.SO), entre muchos otros; estos espacios facilitan al proyecto la focalización de la población, articulando el proceso terapéutico que realizan con las acciones básicas de la metodología.

c) Tercer nivel: Es un nivel de intervención en el que, luego de un respaldo institucional y un proceso de coordinación y logística básico, el orientador (figura encargada de realizar el acompañamiento de incubación del emprendimiento colectivo) organiza a los jóvenes para comenzar a desarrollar la idea de negocio, trabajando desde dos dimensiones: la social y la empresarial. En este nivel, se encuentra también el papel del dinamizador, quien con una mirada global de los procesos en territorio, articula acciones de vinculación entre las empresas acompañadas o entre actores locales.

Entre los actores representados en cada nivel el papel del orientador y el del dinamizador son indispensables.

1. El orientador: Con base en lo descrito en la metodología de acompañamiento e incubación desarrollada por LAINES ${ }^{42}$, es la persona encargada de realizar el proceso formativo a las iniciativas empresariales juveniles, trabajando bajo los principios de Economía Social. Entre sus funciones principales está43:

- Identificar y diagnosticar la situación de vulnerabilidad de las juventudes en sus territorios.

- Buscar y seleccionar grupos e iniciativas empresariales que quieran recibir el acompañamiento.

- Aplicar la metodología a las empresas en sesiones semanales de trabajo. 
- Promover relaciones empáticas, colaborativas, responsables y de compromiso dentro de la Empresa de Economía Social (EES), que se traduzcan en la formación de un equipo autogestivo.

- Alinear el proyecto personal de las y los jóvenes con el proyecto empresarial de la EES.

- Favorecer una cultura de cooperación y colaboración hacia dentro de la EES y hacia fuera de esta.

- Generar redes entre las EES acompañadas con otras EES y con diversos actores.

2. El dinamizador tiene entre sus funciones principales ${ }^{44}$.

- Identificar las necesidades individuales que se puedan colectivizar a partir de los diagnósticos y encuentros con miembros de la comunidad y de las EEs del proyecto.

- Crear lazos de retroalimentación económica entre los actores de un territorio, que posibiliten reproducir de manera ampliada el valor económico en provecho de todos.

- $\quad$ Atender oportunidades que se presenten en el territorio y que tengan impacto en los objetivos del proyecto o que sean de beneficio comunitario, mediante la comunicación constante con actores y miembros de la comunidad.

- Vincular actores clave con la comunidad para promover la apropiación de los componentes del Circuito de Economía Social (CES).

- Dar seguimiento a alianzas, nuevos grupos y procesos que se detonen en el proyecto, a partir de actividades, encuentros y formaciones que promueva el dinamizador.

La operatividad del proyecto se implementa con el dinamizador y el orientador, y es liderada por el aliado estratégico en cada territorio. La estructura organizacional es definida por el aliado. Sin embargo, el esquema común de organización que se ha presentado en la mayoría de territorios se muestra en la figura 2:

44 Id. 


\begin{tabular}{|c|c|c|}
\hline $\begin{array}{c}\text { Coordinación } \\
\text { general del proyecto }\end{array}$ & $\begin{array}{l}\text { Coordinador general } \\
\text { del proyecto }\end{array}$ & $\begin{array}{l}\text { Funciones: } \\
\text { Coordinador general: } \\
\text { - Realizar los vínculos para la implementación } \\
\text { adecuada del proyecto. } \\
\text { - Supervisar el cumplimiento de los objetivos } \\
\text { del proyecto. } \\
\text { - Coordinar y supervisar el trabajo de los } \\
\text { orientadores en campo. } \\
\text { - Supervisar el cumplimiento de metas por } \\
\text { orientador. }\end{array}$ \\
\hline $\begin{array}{l}\text { Equipo coordinador } \\
\text { de orientadores }\end{array}$ & Dinamizador & $\begin{array}{l}\text { Funciones: } \\
\text { - Detonar y articular procesos en territorio } \\
\text { (convocatoria, alianzas, redes). } \\
\text { Dinamizadora operativa } \\
\text { - Realizar acciones de gestión y logística } \\
\text { para la implementación del proyecto. }\end{array}$ \\
\hline $\begin{array}{c}\text { Equipo operativo } \\
\text { del proyecto en } \\
\text { territorio }\end{array}$ & Orientador 2 & $\begin{array}{l}\text { Funciones: } \\
\text { - Búsqueda de jóvenes para } \\
\text { participar en el proyecto. } \\
\text { - Incubar lo emprendimientos } \\
\text { colectivos juveniles. }\end{array}$ \\
\hline
\end{tabular}

Figura 2. Estructura operativa de la Plataforma

Fuente: Elaboración propia con base en LAINES ${ }^{45}$

La asignación de un equipo operativo organizado permite detonar procesos integrales de trabajo, donde los emprendimientos colectivos no se acompañan como ejercicios asilados; por el contrario, se presenta un esquema de articulación en el cual el dinamizador es fundamental para encontrar los espacios de oportunidad para la construcción de redes.

\section{Población objetivo}

La Plataforma, como se ha mencionado, está dirigida a trabajar con un perfil de jóvenes en riesgo, cuya participación se genera mediante un proceso de focalización para medir el nivel de riesgo en el que se encuentran. La convocatoria se realiza de diferentes formas y adecuándose a los distintos territorios, en gran medida, con base en la articulación de alianzas con actores locales que tienen trabajo previo con esta población, por ejemplo:

- Jóvenes internos en centros de rehabilitación por adicción a sustancias psicoactivas.

En los territorios de Tijuana, Jalisco, Morelia y Chihuahua, se acompañan emprendimientos con población masculina en estas condiciones. Las orientadoras acuden a los centros para los procesos de acompañamiento.

45 LAINES, supra, nota 43. 
- Jóvenes internos en Centros de Readaptación Social (CE.RE.So)

En los municipios de Cuauhtémoc, Parral y Chihuahua, se trabaja en total con tres CE.RE.so donde se acompañan emprendimientos colectivos en su mayoría varoniles.

- Jóvenes que laboran en fábricas y maquilas.

En los territorios de Chihuahua y Tijuana, se trabaja con esta población que cotidianamente laboran en horario nocturno, en condiciones precarias de trabajo.

- Jóvenes de origen indígena.

Dentro del proyecto se acompañan a alrededor de seis colectivos mixtos con población de origen tarahumara, en los municipios de Delicias, Cuauhtémoc y Chihuahua. Estos jóvenes con escasos estudios, con poco entendimiento del idioma español, y discriminados por su origen étnico están en un alto riesgo en los entornos urbanos.

- Jóvenes que no se encuentran estudiando ni trabajando.

Con la vinculación a los programas Brigadas Comunitarias de Norte a Sur y Jóvenes Construyendo el Futuro, se está trabajando con esta población en Tijuana y Morelia.

La definición del nivel de riesgo en el que se ubica un joven se realiza mediante la aplicación de una herramienta de focalización que tiene dos objetivos fundamentales: focalizar y evaluar el nivel de riesgo. Esta herramienta se basa en la teoría de la acción situacional, que busca explicar por qué se dan las conductas violentas y parte de proponer que las causas pueden ser: (i) por "propensión", es decir, las condiciones personales que hacen susceptible a una persona a la violencia (conductas personales, historia de la infancia, comportamiento impulsivo, entre otras); y (ii) por "exposición", referidas a las condiciones contextuales que lo exponen a la violencia (inseguridad comunitaria, relaciones familiares, etc.).

La participación en estos dos niveles determinará la condición de riesgo del joven a la violencia. En la tabla 9, se muestra cómo afecta esta combinación. 
Tabla 9. Matriz relacional de la violencia

\begin{tabular}{lll}
\hline \multicolumn{1}{c}{ Propensión (persona) } & \multicolumn{1}{c}{ Exposición (lugar) } \\
\hline Favorable a la violencia & Favorable a la violencia & Adverso a la violencia \\
\hline Adverso a la violencia & La violencia es probable & $\begin{array}{l}\text { La violencia se detona desde la } \\
\text { persona y dependerá más del nivel } \\
\text { de disuasión en el lugar }\end{array}$ \\
& & La violencia es improbable \\
& $\begin{array}{l}\text { La violencia se detona desde el } \\
\text { lugar y dependerá más de las } \\
\text { emociones y las capacidades de } \\
\text { autocontrol del individuo }\end{array}$ \\
\hline
\end{tabular}

Fuente: Elaboración propia con base en Agencia de Estados Unidos para el Desarrollo Internacional (USAID). THRUSTING SUSTAINABLE VIOLENCE AND CRIME PREVENTION APPROACHES IN MEXICO. México D.F.: USAID. (2018).

La herramienta de focalización determina tres niveles de riesgo en los que se puede encontrar un joven según la combinación de las condiciones de propensión y exposición que tenga.

- Nivel 0 (bajo): Jóvenes que enfrentan factores de riesgo bajos y tienen comportamiento de riesgo bajo.

- $\quad$ Nivel 1 (medio): Jóvenes que enfrentan factores de riesgo alto y tienen comportamientos de riesgo iniciales.

- $\quad$ Nivel 2 (alto): Jóvenes que enfrentan factores de riesgo altos y comportamiento de riesgo evidente, pero que aún no entran en conflicto con la ley.

- Nivel 3 (crítico): Jóvenes que enfrentan factores de riesgo altos y comportamientos de riesgo evidentes, con conflicto con la ley.

La Plataforma prioriza el trabajo con el nivel alto y el nivel crítico de riesgo. E nivel alto se refiere a los jóvenes que no tienen cubiertas la mayoría de sus necesidades, por lo que los factores de riesgo se incrementan; por ejemplo, jóvenes que provienen de un núcleo familiar violento o desintegrado, que no estudian o no cuentan con un empleo, y que se inician en el consumo de drogas ${ }^{46}$. El nivel de riesgo crítico lo componen aquellos jóvenes que se encuentran en un contexto de alto riesgo, que ya han cometido actos violentos y tienen conflictos con la ley ${ }^{47}$.

La aplicación de la herramienta de focalización, con una muestra de 276 jóvenes participantes en el proyecto en cinco territorios, arroja los siguientes resultados para

46 Francisco Castellanos García, supra, nota 30.

47 Agencia de Estados Unidos para el Desarrollo Internacional (USAID). PREVENCIÓN DE LA VIOLENCIA JUVENIL: RETOS Y OPORTUNIDADES EN MÉXICO Y AMÉRICA LATINA. MéXico D.F.: USAID. (2018). 
la condición de riesgo: 11,2 \% bajo, 20,2 \% medio, 24,8 \% alto y 43,8 \% crítico. Como se observa, con base en el número de herramientas aplicadas, el mayor porcentaje se encuentra en jóvenes con un nivel de riesgo alto y crítico, con un total del 68,6 \% de la población de jóvenes que se acompaña.

La experiencia de implementación ha mostrado que para impulsar un emprendimiento colectivo, se requiere la conformación de grupos mixtos donde participen jóvenes con alto nivel de riesgo pero también jóvenes o adultos que no se encuentren en esta condición. Esta combinación permite que se genere una red de contención para cuando los jóvenes en alto riesgo quieran desistir por su condición.

\section{MODELO DE INTERVENCIÓN}

El modelo de intervención de la Plataforma está formado por diversos elementos; para la presentación en este artículo, se abordan y se describen los siguientes:

1. Metodología de acompañamiento e incubación ${ }^{48}$, a la cual se hizo referencia al inicio de este artículo.

2. El proceso de seguimiento al equipo de orientadores y dinamizadores mediante la herramienta del coaching cooperativo.

3. Los espacios formativos y de incidencia en prevención de violencias en el acompañamiento a los jóvenes.

\section{Metodología de acompañamiento e incubación}

La metodología contempla dos ejes o ámbitos de acción durante el proceso: el eje del hacer, que incluye los temas empresariales; y el eje del ser, que abarca los temas de desarrollo personal y humano y de conformación de equipo. Para el trabajo, en el eje del hacer o la dimensión empresarial se diseñó una ruta del emprendiendo que contempla cuatro trayectos (figura 3).

Generación de idea de negocio
Construcción de modelo de negocio
Desarrollo del modelo de negocio
Profesionalización del negocio

Figura 3. Trayectos de la ruta del emprendimiento

Fuente: Elaboración propia con base en los cuatro trayectos de la ruta del emprendimiento ${ }^{49}$

48 IBERO Puebla, supra, nota 10.

49 Laboratorio de Innovación Económica y Social (LAINES). REPORTE ANUAL PCSCJM 2018. Puebla: LAINES. (2018). 
Conociendo la importancia de la dimensión social en los emprendimientos colectivos, el LAINES ha desarrollado una metodología de acompañamiento a los equipos: el coaching cooperativo, que une los principios del coaching humanista y los de la Economía Social. Desde esta perspectiva, se promueve el desarrollo humano y del equipo a lo largo del proceso de incubación.

El coaching cooperativo ${ }^{50}$ es entendido como una metodología que facilita procesos de colaboración a partir de la toma de conciencia y de responsabilidad de la persona y su relación con otras para transformar su realidad y juntos lograr su bien-ser y su bien-estar.

Adicional a las dimensiones empresarial y social, la metodología de incubación y acompañamiento desarrollada por LAINES ${ }^{51}$ contempla la dimensión de innovación, que comprende que el ejercicio empresarial debe diferenciarse profundamente del resto de iniciativas; por ello, los conceptos, los bienes y los servicios que los colectivos ofrecen al mercado deben tener una búsqueda constante de innovación. En particular, se incentiva que los jóvenes contemplen componentes tecnológicos tanto en la producción, como en el producto mismo de sus emprendimientos.

La dimensión de innovación también contempla la búsqueda y creación de espacios de transformación social, de una generación diferente de cultura y formas de relacionarse en su entorno próximo y en la comunidad; se pretende que desde esta dimensión el resultado abone a desarrollar mejores maneras de convivencia y bienestar ${ }^{52}$. Así mismo, se impulsa a los colectivos a acercarse a problemáticas sociales para ofrecer una solución innovadora que resuelva las necesidades del colectivo y de su territorio. Se pretende sensibilizar e incentivar a los jóvenes a involucrarse de manera proactiva en la detección y satisfacción de las necesidades colectivas no solo a través de la incubación de una empresa de Economía Social, sino también de otros ejercicios económicos o solidarios.

El objetivo central de la última dimensión contemplada en la metodología es la creación de redes. Esta dimensión representa un pilar esencial para la sustentabilidad de las empresas, ya que es el espacio donde se llevan a la práctica las actitudes basadas en la solidaridad, el compromiso y la responsabilidad, y ello implica la toma de acuerdos democráticos en un nivel superior. Es a partir de esta dimensión que se gesta la oportunidad de generar la intercooperación; se pretende que en todo momento la empresa se pueda rodear y fortalecer con actores con los que se puedan generar relaciones de beneficio mutuo a través de ejercicios como consumo colaborativo,

50 IBERO Puebla, supra, nota 10.

51 Id.

52 Id. 
aprovechamiento de bienes y servicios mancomunados, etc. Una de las finalidades que se persigue, además de lo relacional, es la reducción de los costos marginales que supondría hacer las tareas de manera individual ${ }^{53}$.

En la figura 4, se presenta el proceso de incubación en las diferentes dimensiones que lo componen y que fueron explicadas en párrafos anteriores. También, se presenta la manera como se va conformando la Empresa de Economía Social. Es importante explicar en detalle el proceso que se vive en la dimensión social, ya que es allí donde los jóvenes reportan importantes cambios.

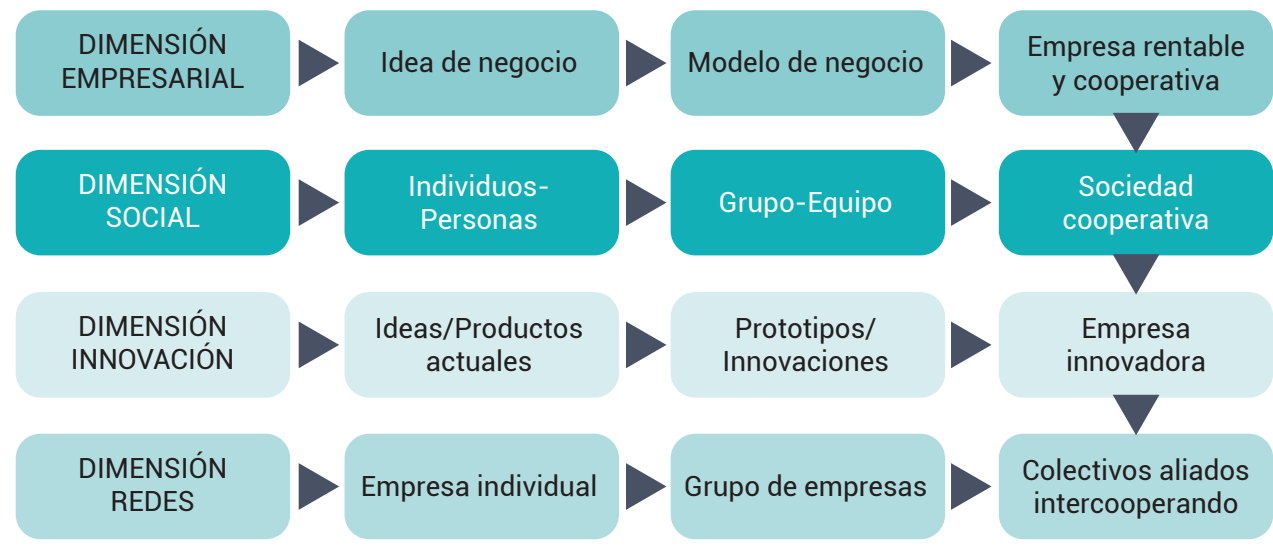

Figura 4. Hoja de ruta de la incubación de la Empresa de Economía Social Fuente: Elaboración propia con base en IBERo Puebla. METOdología PARA EL ACOMPAÑAMIENTO E INCUBACIÓN DE EMPRESAS de ECONomía Social. Puebla: Universidad Iberoamericana Puebla. (2017).

Para comprender la dimensión social, se plantea que a través del acompañamiento se impulse un proceso de transformación personal y colectiva, tal como se muestra en la figura 5:

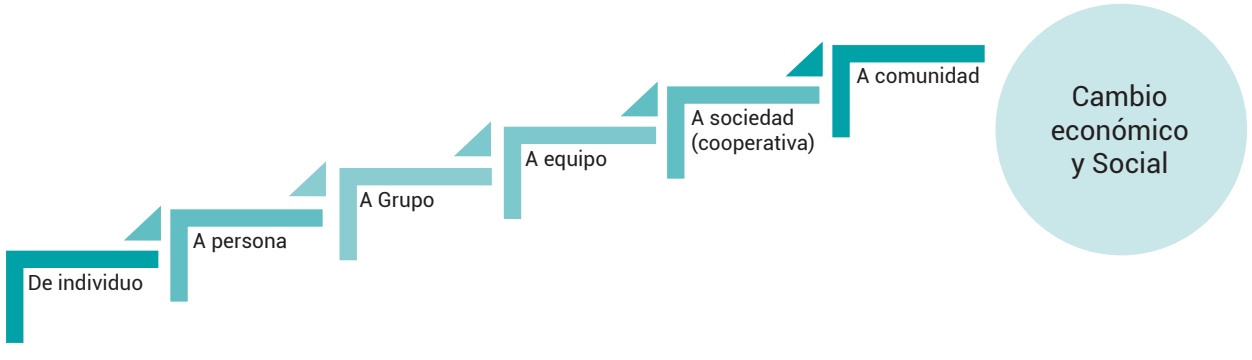

Figura 5. Pasos de la dimensión social

Fuente: Elaboración propia con base en IBERo Puebla. METOdología PARA EL ACOMPAÑAMIENTO E INCUBACIÓN de EMPRESAS de EConomía Social. Puebla: Universidad Iberoamericana Puebla. (2017).

53 IBERo Puebla, citado en Carolina Macías, supra, nota 4. 
En la figura 5, se observa un modelo que responde a la necesidad de integrar a los colectivos desde la dimensión social, pasando por un proceso que va del individuo al grupo, del grupo al equipo, del equipo a la sociedad y de la sociedad a la comunidad. Este proceso no puede desarticularse de la incubación de los emprendimientos; por el contrario, es lo que permite fortalecer el proyecto juvenil, ya que al hacer énfasis en la consolidación del equipo, se presume que habrá mayor permanencia de los colectivos. En el momento actual, la mayoría de los emprendimientos están en el proceso de grupos y de equipos.

Las personas que conforman un colectivo juvenil cuando inicia el acompañamiento son individuos condicionados por el sistema capitalista en el que la lógica es individualista y egocéntrica. El ser vivo es con independencia de los otros. A partir de ahí inicia el trabajo en la dimensión social, con el objetivo de integrar un colectivo en un proyecto común en el que todos los participantes desarrollen sus potencialidades al tiempo que aprenden o fortalecen las habilidades que les permitirán ser autogestivos para culminar con éxito el proceso de incubación y dar nacimiento a su empresa, con la que, eventualmente, logren impactar a nivel económico y social primero en su entorno más próximo y posteriormente en su territorio.

Conforme se va trabajando en la incubación de individuos se pasa a las personas. De acuerdo con Abraham Maslow ${ }^{54}$, una persona es un ser singular e irrepetible, con poder de reflexión, y respeto a sí mismo, a los demás y a su entorno; con identidad propia, cuenta con inteligencia y voluntad. En las sesiones de acompañamiento, no solo se abordan temáticas empresariales sino que además se hacen espacios de reflexión con los jóvenes para ir desarrollando y fortaleciendo habilidades vitales como la autoestima y la comunicación asertiva. Se elabora un proyecto de vida del que se parte para plantear un futuro proyecto que les mantendrá unidos; sin embargo, parte fundamental de la metodología es mantener a los jóvenes implicados en los dos ejes, el del ser (que pretende el autodesarrollo) y el del hacer (que tiene que ver con la empresa).

Después, y como parte natural del proceso, de persona se pasa a grupo, lo que implica poner la voluntad de perseguir un objetivo común; sin embargo, de ahí se tiene que transitar hacia la contrucción de un equipo y esto se trabaja a partir de la construcción del corazón ideológico de su empresa, que les permita compartir una misión y una visión, que se definan los valores que comparten y los que regirán su ser y su quehacer como colectivo. Según la Escuela Andaluza de Economía Social ${ }^{55}$, los integrantes de un equipo interactúan, discuten y piensan de forma coordinada y coo-

54 Citado en IBERo Puebla, supra, nota 10.

55 Id. 
perativa, tienen una estrategia común, comparten responsabilidades y sus miembros se complementan.

Una vez que está definida la idea de negocio en el emprendimiento, se empieza a construir el modelo de negocio y se define la estructura organizacional con la consecuente asignación de roles. Este paso es crucial en el desarrollo del emprendimiento, ya que la mayoría de los jóvenes lo experimentan como un proceso de dominio o de relación con la autoridad, y es también un momento en el que los jóvenes descubren nuevos tipos de relaciones y se abren a experiencias de diálogo y toma de decisiones, por lo que al término de esta etapa se ha constituido el equipo.

A partir del trabajo constante y disciplinado del colectivo juvenil, y con el acompañamiento y compromiso de su orientadora, se hacen progresos importantes que permiten transitar de un equipo a una sociedad que coopera; es decir, se consolida la Empresa de Economía Social, que se define como el conjunto de personas que se relacionan entre sí, de acuerdo con determinadas reglas de organización consensuadas y que se rigen bajo los principios de la Economía Social.

Por último, se pretende que todo el proceso de transformación madure al punto de llevar a los colectivos hacia una comunidad que coopera, es decir que sean personas que viven o comparten un territorio bajo ciertas reglas con intereses compartidos y que se relacionan para lograr la sustentabilidad y mejorar sus condiciones de vida, alineados a los principios y valores cooperativos ${ }^{56}$.

Cuando un colectivo se asume como un equipo, desarrolla su modelo de negocio y tiene una meta clara y un objetivo común que lo articula; solo entonces se puede aspirar a que se vincule con la comunidad como actor de cambio. Es en este proceso cuando se transita de un equipo a una sociedad; este proceso requiere también actores y relaciones que puedan fortalecer las acciones de las empresas, por eso necesita la creación y el fortalecimiento de redes.

La visión de la metodología, al igual que la del LAINES, se basa en la frase "No hay transformación social sin transformación económica, no hay transformación económica sin transformación grupal y no hay transformación grupal, económica y social sin transformación personal"57.

La metodología vincula la dimensión social y la empresarial; en las dos dimensiones se acompaña a los jóvenes durante el proceso de desarrollo de sus empresas, y se considera fundamental hacer énfasis en los temas y contenidos de la ruta que abonan a la construcción de seguridad ciudadana ${ }^{58}$.

\footnotetext{
56 IBERo Puebla, supra, nota 10.

57 Id.

58 Id.
} 
A su vez, la metodología plantea cuatro enfoques o ejes transversales que orientan las acciones desarrolladas durante la incubación y el acompañamiento de los colectivos juveniles; es gracias a estos que se propicia la reflexión y acción de las empresas y sus integrantes en todo momento, lo cual permite una alineación de los proyectos con aspectos fundamentales que abonan a la construcción de seguridad ciudadana y que, asimismo, están en concordancia con valores y principios de la Economía Social. Los enfoques contemplados por la metodología son: Seguridad Ciudadana, Juventudes, Género y Medio Ambiente ${ }^{59}$.

El enfoque de juventudes que prevé la Plataforma se refiere a la toma de conciencia, sobre todo por parte de quien orienta el proceso, de quiénes son y cómo viven estos sujetos a quienes se dirige el proyecto. En un entorno marcado por la violencia y la falta de oportunidades, las preguntas fundamentales son: ¿quiénes son estos jóvenes?, ¿cuáles son esas violencias a las que están expuestos y que viven de manera cotidiana y, en muchas ocasiones, normalizada?, ¿cómo se pueden fortalecer sus competencias para generar mayores oportunidades a través de la Economía Social? Con estas reflexiones en mente, los orientadores y personas allegadas al proyecto parten de una comprensión profunda y una empatía por el proceso fundamental de vida que enfrentan las personas en esta etapa etaria.

Es en esta fase del desarrollo (cuando la identidad termina de formarse, cuando encuentran su vocación, cuando conocen a su pareja sentimental y en muchos casos empiezan a conformar su propia familia) que está fuertemente presente la necesidad de pertenencia y valoración por parte de sus pares y de la misma familia y sociedad. También, en esta etapa se da una especie de emancipación de la autoridad paterna y del mundo adulto. Todo ello conduce o deriva en su independencia económica, intelectual y valoral ${ }^{60}$.

Si bien en su mayoría los jóvenes comparten todos los aspectos mencionados como proceso de vida, la manera en que responden a ellos, aunada a las adversidades que enfrentan por su personalidad y sus contextos, demanda entender y reconocer sus particularidades.

En particular para la Plataforma, hablar de juventudes en riesgo es comprender que no son las personas jóvenes el "problema" a enfrentar, sino que hay situaciones socioeconómicas que los vulneran y los ponen en riesgo; en ese contexto responden desde las posibilidades que encuentran y con los recursos que tienen según su situación. Son estas situaciones socioeconómicas y culturales las que requieren ser

59 Id.

60 Id. 
intervenidas para posibilitarles otras oportunidades desde la propuesta de la Economía Social, que pretende el empoderamiento y el liderazgo juvenil61.

El enfoque de Seguridad Ciudadana estipula que "La Plataforma, en oposición a posturas de estigmatización y criminalización juvenil, apuesta por el desarrollo de la resiliencia en esta población para construir posibilidades de vida y trabajo que les beneficien personal y grupalmente, a su comunidad y al medio ambiente"62.

Como ya se ha mencionado, lo que se pretende en la orientación a los grupos de emprendimientos colectivos juveniles es dotarles de herramientas empresariales, de innovación tecnológica y de conformación de redes de Economía Social, pero muy particularmente se pide trabajar con mucha fuerza y de manera muy cercana en la dimensión personal y social, así como en el desarrollo de habilidades para la vida y la convivencia. Entre estas últimas se destacan: autoconocimiento, empatía, pensamiento crítico y creativo, manejo de estrés y de emociones, comunicación efectiva, asertividad, relaciones interpersonales, solución positiva de conflictos y autocuida$\mathrm{do}^{63}$. Todo ello abona al desarrollo de la resiliencia que se persigue con el ejercicio de incubación de emprendimientos colectivos juveniles.

Una de las definiciones de resiliencia más pertinente para el trabajo con las poblaciones juveniles en riesgo es la que plantea Quintero ${ }^{64}$, ya que tiene un enfoque integral y humanista que afirma que: es la aptitud de reaccionar positivamente a pesar de las dificultades y la posibilidad de construir basándose en las fuerzas propias del ser humano. La importancia de esta visión radica en la implicación del fenómeno de aprendizaje que se da en circunstancias adversas y que permite, a partir de este, proyectar un futuro diferente, más positivo, basado en las experiencias reflexionadas.

Por otro lado, el enfoque de género también es un pilar fundamental para el trabajo con las juventudes. Se plantea que para lograr una transformación económica y social, es necesario transformar primero las relaciones más próximas y construirlas desde la paz. Esto solo se puede hacer a partir de la equidad, de la inclusión de la diversidad y de cuestionar los roles de género rígidos que son causantes y reproductores de violencia ${ }^{65}$.

Se entiende por género aquellos mandatos sociales sobre cómo cada persona debe vivir su sexualidad al ser hombre o mujer. Los roles de género rígidos cuestionan y condenan aquellas formas de vida que no encajan con el estereotipo establecido,

\footnotetext{
$61 \mathrm{Id}$.

$62 I d$.

63 Id.

64 Citado en Francisco Castellanos García, supra, nota 30.

65 IBERo Puebla, supra, nota 10.
} 
rompen la capacidad de elegir cómo se quiere ser y, por lo tanto, violentan la libertad y la identidad. En consecuencia, las oportunidades, los derechos e incluso las capacidades de las personas se ven limitadas ${ }^{66}$, dado que: "La equidad de género es la distribución equitativa de los derechos, las obligaciones, las oportunidades y los recursos entre las personas, a partir del reconocimiento y el respeto de las diferencias entre mujeres y hombres en la sociedad" (Collectiu Pun 667).

La Plataforma se identifica como una importante oportunidad para sanar las relaciones más próximas entre pares, por lo que tener información pertinente y espacios de diálogo es lo que se promueve desde este espacio. Así mismo, se pretende una equidad de género en lo privado que lleve a reorganizar el trabajo reproductivo, doméstico o del cuidado, que se generen relaciones más horizontales y que los valores cooperativos se vivan desde este ámbito de la vida, que todo empiece en lo individual y que se lleve a lo colectivo.

Por último, se encuentra el enfoque de medio ambiente. Es importante señalar que en la Plataforma el medio ambiente implica mucho más que los espacios naturales, ya que es todo aquello que rodea a los seres vivos: "Es el conjunto de factores físicos, químicos, naturales, culturales y sociales en que los organismos están inmersos, las relaciones que se generan y que propician las condiciones para la vida"68.

De esta manera, es fundamental pensar en el impacto que tienen las acciones individuales y colectivas, positivas y negativas, en torno al medio ambiente. El acompañamiento en este sentido tiene que reflejar dicha conciencia y cuidado desde el planteamiento del corazón ideológico del emprendimiento colectivo juvenil, sus actividades económicas a desarrollar, su modelo de negocio y la forma en que se comportan los integrantes del colectivo en el día a día. Cómo van trasladando un estilo consumista inconsciente a un mayor cuestionamiento y atención a las verdaderas necesidades.

\section{Proceso de acompañamiento al orientador}

El modelo de acompañamiento al equipo de orientadores está diseñado para guiarlo en el proceso de búsqueda de jóvenes, conformar colectivos e incubar emprendimientos, alineado con la metodología. Por parte del equipo de la IBERo Puebla, se realiza un acompañamiento de dos horas semanales a cada uno de los orientadores en los territorios, con la intención de conocer el avance de los colectivos, la necesidad

\footnotetext{
66 Id.

67 Citado en IBERo Puebla, supra, nota 10.

68 IBERO Puebla, supra, nota 10.
} 
de contenidos para las sesiones y la transmisión de herramientas, ejemplos y experiencias que potencialicen el desarrollo de las empresas ${ }^{69}$.

Durante la incubación de los colectivos, se dan dos procesos de acompañamiento que ocurren de manera simultánea. La orientadora acompaña a sus colectivos y la coach del equipo LAINES acompaña a las orientadoras con un doble objetivo: que la implementación de la metodología y la ruta sean adecuadas, y que se dé el cumplimiento de metas y objetivos; esto se logra a través de la herramienta del coaching cooperativo. A continuación, se muestra el proceso de sesiones de la coach a la orientadora y de la orientadora al emprendimiento ${ }^{70}$. La figura 6 muestra los cinco momentos que se desarrollan en una sesión de seguimiento. En el acompañamiento de la coach a la orientadora, la sesión tiene como objetivo tres elementos esenciales:

1. Conocer los avances de los emprendimientos.

2. Dar apoyo y asesoría a problemáticas presentadas en las sesiones de acompañamiento.

3. Revisar evidencias de las sesiones realizadas.

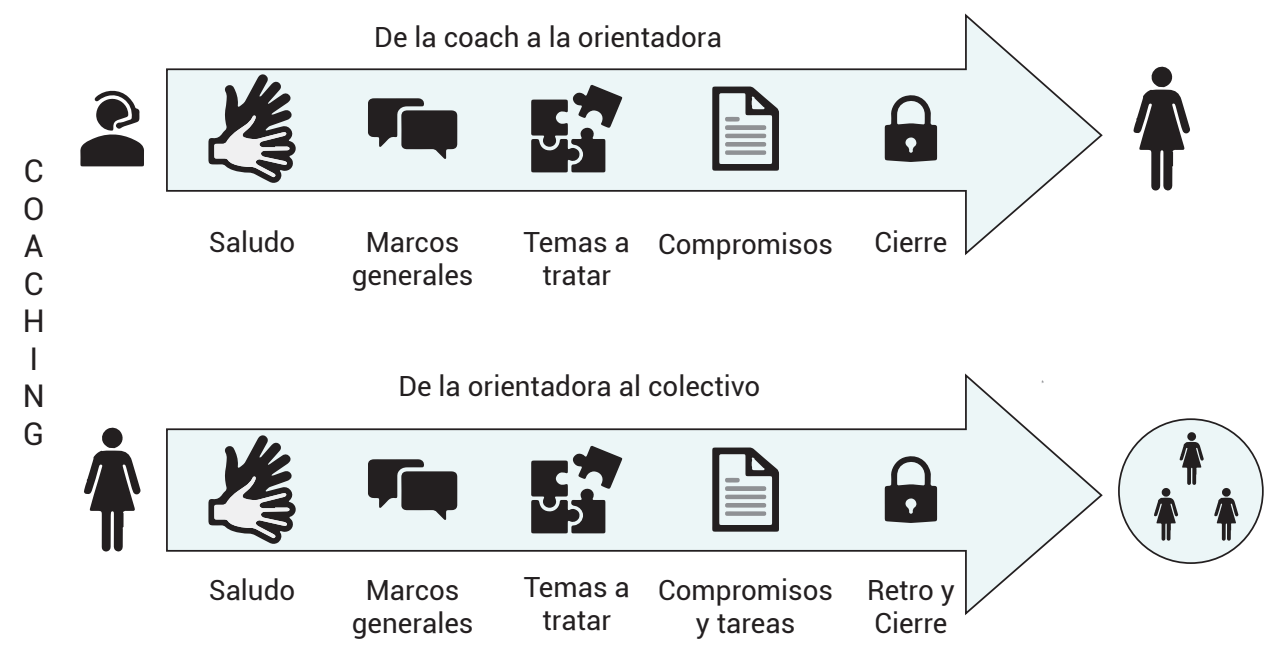

Figura 6. Proceso de acompañamiento

Fuente: Elaboración propia con base en Carolina Macías. Incubación de empresas juveniles de Economía Social, modelo para prevención de violencia y construcción de seguridad ciudadana juvenil Caso: Grupo BSCH. ReVISTA IBERo 67. Abril-mayo 2020. 
Existen momentos clave durante las sesiones de incubación de la orientadora al colectivo, en los que se modelan buenas prácticas a los jóvenes y se intenciona el desarrollo de hábitos que favorezcan no solo el avance de la empresa, sino también el desarrollo personal y colectivo. Saludar y validar el estado en el que llegan los jóvenes sienta las bases para un trabajo más eficiente.

Poner marcos en la sesión anticipa tanto la temática a abordar como los lineamientos y acuerdos que se han tomado para un buen funcionamiento del equipo. Los compromisos son actividades y tareas que los propios jóvenes se asignan considerando el avance que requieren lograr entre una sesión y otra; esto los compromete a trabajar de manera colectiva entre las sesiones. Hacia el cierre de la sesión, la orientadora da y recibe retroalimentación con el objetivo de practicar la mejora continua, la reflexión, la autoevaluación y la comunicación asertiva. Finalmente, se asumen compromisos de ambos lados y se acuerda la siguiente sesión $n^{71}$.

Como se mencionó en párrafos anteriores, el proceso de acompañamiento tanto al equipo de orientadores, como al trabajo que el orientador hace con el colectivo se basa en la herramienta de coaching cooperativo. Esta es la herramienta que emplea la orientadora para generar los procesos humanos de transformación, acompañando al colectivo en las etapas de individuo, persona, grupo, equipo y sociedad (cooperativa).

Los principios del coaching cooperativo que se utilizan son (figura 7):

1. A partir de los demás, me fortalezco.

2. Reconozco mis potencialidades, capacidades, debilidades y estas se fortalecen con los demás.

3. La Economía Social es un medio y un modo de vida que genera identidad.

4. Los jóvenes tienen el potencial para lograr los cambios que desean.

71 Id. 


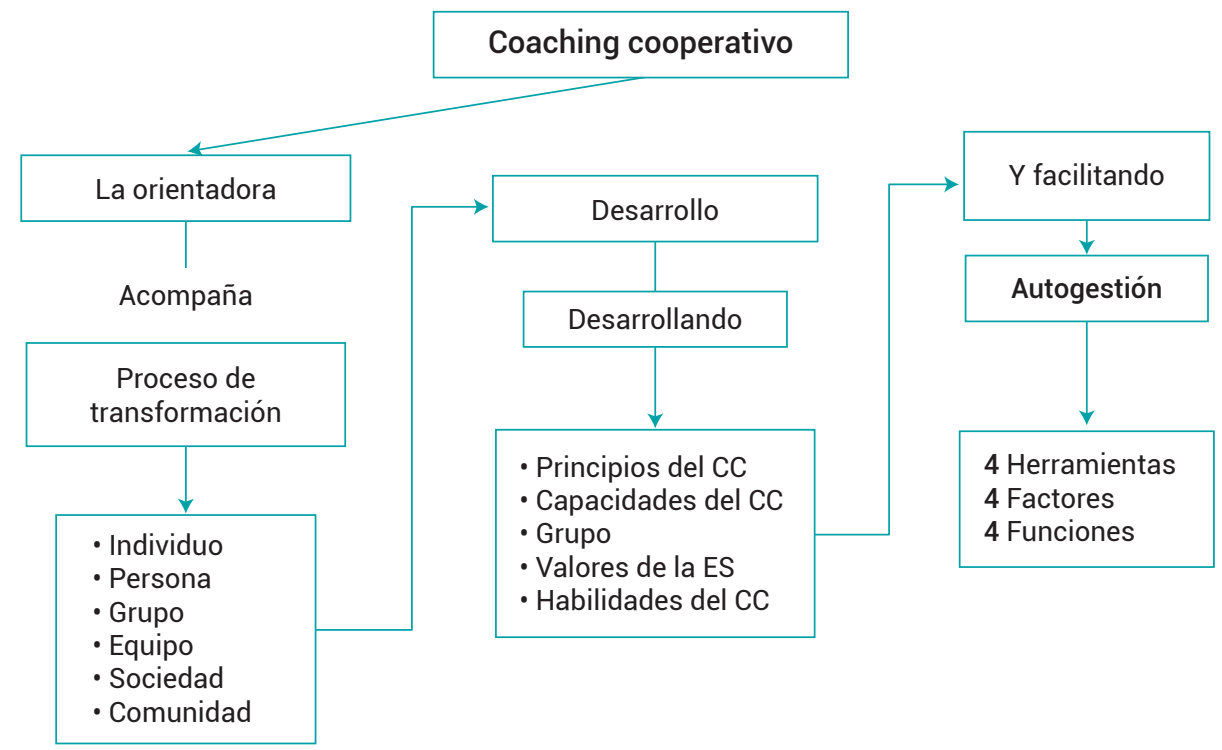

Figura 7. Proceso de trabajo desde el coaching cooperativo Fuente: Elaboración propia con base en LAINES ${ }^{72}$

En la herramienta del coaching cooperativo, se utilizan cuatro principales habilidades de comunicación: apoyo, escucha, preguntas efectivas y retroalimentación (dar y recibir). El desarrollo de este proceso debe ser desde la autogestión y para ello se utilizan cuatro factores (gestión del cambio, interiorización de metas y objetivos, aceptación y manejo de la diversidad, y búsqueda del modelo de funcionamiento). A su vez, estos factores incluyen cuatro funciones (planear, prever, dirigir y controlar) y cuatro herramientas de gestión (planeación estratégica, gestión del tiempo, comunicación efectiva y creatividad); todo lo anterior está basado en los principios y valores de la Economía Social y el cooperativismo.

Estas habilidades, en un primer momento, generan un cambio positivo en las orientadoras, el cual complementa los procesos formativos que se tienen con ellas. Es durante el desarrollo de estas habilidades que las orientadoras pueden identificar los cambios positivos en sus propias vidas. Estas habilidades se van desarrollando por medio de la implementación de la ruta del emprendimiento, ya que la práctica cotidiana permite transmitir las habilidades de manera efectiva a los jóvenes, y que ellos a su vez puedan transmitirlas en su círculo cercano y en sus comunidades. A continuación, se enumera una lista de cambios que las orientadoras han identificado en ellas mismas:

72 IBERo Puebla, supra, nota 10. 
1. Fortalecimiento de capacidades en temas empresariales con enfoque de economía social, construcción de equipo y modelo de negocio.

2. Seguridad en sí mismas. A través del proceso de coaching reconocen sus propios talentos y habilidades, y los potencian.

3. Desarrollo de habilidades como mediadoras en la transformación positiva de conflictos.

4. Son referentes positivos para los jóvenes que acompañan, las orientadoras aprenden a valorar y reconocer este papel.

5. Experimentarse como agentes de cambio.

Dentro del proceso de acompañamiento realizado por las orientadoras, se van presentando distintos escenarios y problemáticas; ante ello, se vio la necesidad de generar espacios de encuentro y diálogo entre todas las orientadoras de la Plataforma, donde intercambian experiencias, aprendizajes, buenas prácticas y también sus obstáculos. Se ha implementado aproximadamente un espacio bimestral de diálogo entre ellas.

Con base en estas funciones, para el acompañamiento a esta figura, se realiza un contacto quincenal entre la IBERo Puebla y el dinamizador de cada zona vía llamadas telefónicas y mensajería instantánea. Cabe mencionar que la comunicación con el dinamizador, dada la dinámica con que funcionan las instituciones y los territorios, es menos estructurada.

\section{Proceso formativo de prevención dentro de la metodología}

Al ser los procesos de prevención de violencias el centro del proyecto, dentro de la metodología están presentes, en la dimensión social, dos elementos fundamentales que abonan a la construcción de seguridad ciudadana: la transmisión de los talleres desde la dimensión social y la aplicación en campo de acciones de gamificación desde la dimensión social.

a) Talleres desde la dimensión social: Corresponden a una serie de cinco talleres que se aplican con los siguientes objetivos.

- Seguridad Ciudadana Juvenil: Transmitir a los jóvenes conceptos básicos de seguridad, y practicar una herramienta para la resolución positiva de conflictos y la no violencia. 
- Habilidades para la vida (talentos y autoestima): Fortalecer en los jóvenes el reconocimiento como seres valiosos y aplicar una herramienta para la identificación de sus talentos y habilidades.

- Proyecto de vida: Acompañar a que los jóvenes identifiquen las dimensiones fundamentales en sus vidas: familia, pareja, salud, trabajo, etc., con el objetivo de alcanzar una vida plena. Del mismo modo, trazar metas específicas a corto plazo para llegar a ello.

- Habilidades para la vida (comunicación): Practicar herramientas de comunicación efectiva y no violenta, y de retroalimentación asertiva para resolver un conflicto.

- Habilidades para la vida (autoliderazgo): Ayudar a que los jóvenes identifiquen sus emociones, generen empatía y apliquen una herramienta para el manejo asertivo y positivo de sus emociones.

- Finanzas y autoestima: Sentar las bases para que los jóvenes hagan un uso responsable de sus recursos y esto abone a su seguridad económica.

La implementación de dichos talleres ha generado reflexiones significativas en los jóvenes para su desarrollo. Por ejemplo, el taller de finanzas personales, según testimonios de los participantes, les ha ayudado a administrar de manera más adecuada los recursos que ya tienen, disminuir gastos irrelevantes y generar una propuesta de ahorro que se traduzca en un fondo de inversión para su emprendimiento. El taller de proyecto de vida y el de talentos y autoestima han ayudado a que los jóvenes vislumbren un nuevo enfoque en su vida, a que le demuestren a su familia que pueden concretar acciones y alcanzar metas, a que se reconozcan con capacidades y habilidades que pueden aportar, y a ampliar su panorama de aspiraciones. El taller de comunicación y autoliderazgo ha permitido que los jóvenes mejoren sus relaciones interpersonales, lo que ha representado una mejor convivencia y manejo del conflicto dentro de la empresa.

b) Acciones de gamificación.

La metodología aborda tres fases de gamificación que se traducen en la implementación de acciones concretas en la comunidad, planteadas como retos desde tres dimensiones:

- Dimensión social: Una acción comunitaria que abone a la Seguridad Ciudadana (taller deportivo, taller artístico en el espacio público, pinta de mural, recolección de basura, etc.). 
- Dimensión empresarial: Validación, con clientes y proveedores, de elementos del modelo de negocio.

- Dimensión de redes: Acción colectiva con otras empresas para la creación de redes y resolución de una necesidad.

De las tres dimensiones de la gamificación, la dimensión social es la más importante en relación con la Seguridad Ciudadana Juvenil. Estas acciones se aplican en todos los territorios. Para poder ejemplificar las acciones que se han realizado, se mencionan las siguientes:

- En Ciudad Juárez, Chihuahua, en la colonia Fray García de San Francisco, el emprendimiento de serigrafía Señor Pulpo impulsó la acción "San Pancho Color 2", que consiste en la pinta de murales e intervenciones urbanas de distintos artistas en la comunidad con el objetivo de mejorar el aspecto de la colonia.

- En Tijuana, Baja California, el emprendimiento Family Tattoo rehabilitó una casa abandonada, utilizada como lugar de venta y consumo de drogas. El objetivo es impulsar una Casa de Arte a donde otros jóvenes puedan llegar y sentir como un espacio cómodo y seguro.

- En Tijuana, Baja California, el emprendimiento Pincelitos, dedicado a la organización de fiestas infantiles, y el emprendimiento Sepanka, servicio de restaurante, visitaron el albergue migrante Agape, donde organizaron un taller de seguridad ciudadana con niñas y niños, y en conjunto habilitaron la cancha deportiva y pintaron un mural.

- En Morelia, Michoacán, el colectivo Boutique organizó un taller de estilismo para un grupo de veinte mujeres en una colonia marginada en la periferia de la ciudad. El taller pretende transmitir una técnica que pueda generar un ingreso para las mujeres participantes.

- En Guadalajara, Jalisco, varios jóvenes de los colectivos acompañados en la Plataforma organizaron un encuentro en el centro de rehabilitación México Me Necesita, donde con música rap y grafiti los jóvenes expresaron sus emociones y mostraron cómo la Plataforma está incidiendo en la prevención de violencias. 


\section{PRESENTACIÓN DEL CASO}

Con base en la experiencia que se ha generado en el LAINES y desde el rol de coaches que acompañan procesos de la Plataforma, se presenta una revisión de casos que han sido relevantes dados los elementos cualitativos que se han recuperado a partir de su incubación. El interés particular, en una primera instancia, es observar el proceso de transformación en cuanto a la dimensión social de parte de los miembros de los colectivos.

A partir de los análisis de lo que se va observando y sistematizando de los diferentes procesos, se diseñarán de manera conjunta con los aliados que implementan en los territorios, y como segunda etapa del proceso de investigación, varios indicadores que describan el impacto del ejercicio de emprendimiento en clave de Economía Social en la prevención de la violencia, en términos de reducción de factores de riesgo e incremento de factores de protección que abonen a una construcción de seguridad ciudadana. El seguimiento que se ha hecho de los colectivos por parte de orientadores y coaches ha permitido obtener información puntual y valiosa para ser compartida.

El primer caso hace referencia a un emprendimiento que inició hace dieciocho meses, aproximadamente, con unos hermanos gemelos que tenían el límite de edad permitido para ser usuario de la Plataforma. Llegaron al proyecto invitados por otro joven que ya había iniciado el proceso. Todos ellos eran vecinos de una colonia ubicada en la periferia de la ciudad de Chihuahua, catalogada como polígono de atención prioritario por presentar altos niveles de rezago urbano y social.

Uno de los gemelos trabajaba como intendente en un hospital, mientras que el otro trabajaba en un taller mecánico pintando carros. Tenían la inquietud de hacer playeras y de ahí surgió la idea de poner un negocio de serigrafía y sublimado. Se ha observado que, sobre todo en los contextos más urbanos, la confianza es algo que cuesta más trabajo generar y conservar. En el grupo del colectivo S, existía desconfianza hacia el orientador, pues tenían la mala experiencia con el sector del Gobierno que en muchas ocasiones ofrece apoyos y hace promesas que no cumple.

Poco a poco y a raíz de la visita constante del orientador, empezaron a darles mayor seriedad a las sesiones para avanzar con el proyecto. Pronto, los jóvenes fueron haciendo a un lado la timidez y comenzaron a comunicarse mejor. Lograron conseguir prestado algo de maquinaria. Al poco tiempo de haber iniciado la producción de las playeras, un tercer joven se acercó a pedir trabajo; sin embargo, siguiendo el esquema de Economía Social, le explicaron al joven que si efectivamente demostraba interés, podría convertirse en socio. La ventaja del tercer joven es que ya había trabajado en un taller de serigrafía, por lo que tenía esa fortaleza que les faltaba los gemelos. 
Comenzaron a trabajar en un local muy pequeño por el que les cobraban una renta simbólica en apoyo al proyecto de los jóvenes. Cuando todo iba iniciando, la ganancia del colectivo era marginal: después de cumplir con sus pagos, tenían que compartir una sopa individual instantánea para poder comer algo. Su ánimo y confianza en sí mismos iba fortaleciéndose; el más retraído de los tres era el tercer joven, realmente interactuaba poco con los gemelos y poco menos con el orientador.

Muy al inicio, los jóvenes se dieron cuenta de que la calidad en la atención y en el servicio era fundamental, pues su aspecto físico podría ser una barrera para conseguir clientes. Por su apariencia podían pasar por jóvenes pandilleros, porque tiempo atrás lo fueron; los resultados en el instrumento de focalización indicaron dos integrantes en nivel alto y uno más en nivel crítico.

Uno de los cambios que empezaron a registrarse en los jóvenes es que ahora invertían más su tiempo en su capacitación en lugar de irse de fiesta. Los jóvenes comparten que todo el tiempo están viendo tutoriales para aprender cómo hacer las cosas, "porque no se le debe decir que no a un cliente, aunque eche uno a perder al principio, ya con la práctica va saliendo... Hubo trabajos que les perdimos porque no sabíamos bien", comenta el tercer joven.

Con el tiempo, el colectivo empezó a vender más y a conseguir clientes. La ubicación del local no les permitía estar visibles y la persona que les había prestado la maquinaria se las pidió de regreso. En ese momento de crisis, decidieron buscar otro local y solicitar un préstamo para adquirir su propia maquinaria. Su plan de negocios estaba ya concluido, lo que les permitía dar mayor certeza al momento de hacer la solicitud de recurso.

A estas alturas, todos se desenvuelven con mayor naturalidad y el discurso ha cambiado en términos de lo que creen que es posible alcanzar, pues al inicio pensaban que podrían tener un local en un plazo que superaba los cinco años; hoy tienen un local mejor ubicado, de mayor tamaño y han adquirido las máquinas con el préstamo que les fue otorgado. Están haciendo un ejercicio de ahorro que les permite pagar el préstamo y saben que en un lapso de dos años podrán comprar más maquinaria para abrir otra sucursal.

En el camino, un cuarto joven entró al colectivo; trabaja en la maquila pero tiene aptitudes para las ventas, sus habilidades le han dado oxígeno al colectivo y ahora todos aprenden de todos. Saben que les toca hacer de todo y siguen profesionalizándose. Han tomado cursos de mercadotecnia digital y tienen actividad en las redes sociales. Al terminar el curso, les otorgaron un diploma y el chico que era más introvertido cuenta con mucho entusiasmo cómo fue a darle a su mamá el diploma: "Nunca antes había tenido una cosa de estas". 
El espacio de trabajo también lo ponen al servicio de jóvenes que quieran aprender y que quieran trabajar, porque eventualmente necesitan ayuda con algunos pedidos grandes. Las ventas que están generando van de los 20000 a los 30000 pesos mensuales... ya no comen sopa instantánea.

Lo que refieren como lo más valioso del proceso, además del aprendizaje empresarial, es la confianza que han desarrollado en sí mismos y que pueden identificar que tienen talentos que ponen al servicio del propio colectivo para el crecimiento de todos. Saben que la fortaleza está en la unión de esos talentos, de las diferentes experiencias y de sus personalidades, han llegado a conocerse y como en muchos otros casos, mencionan que su colectivo es como su otra familia.

Se les ve felices haciendo su trabajo y con claridad acerca del futuro. Sus conductas de riesgo definitivamente disminuyeron, pues "ahora tienen qué hacer y es algo bueno".

El colectivo B está integrado por cinco hombres jóvenes en edades entre 23 y 32 años. Inician su proceso de incubación en agosto de 2018, se dedican a la producción de huevo ranchero. Actualmente, están buscando financiamiento para crecer de 123 a 2000 gallinas, lo que les permitirá una producción que cubra la demanda identificada en el territorio. El pasado 29 de mayo de 2019, se constituyeron legalmente como la sociedad cooperativa Grupo BSCH con el apoyo de la Secretaría de Innovación y Desarrollo Económico del estado de Chihuahua.

La historia del colectivo comienza cuando el orientador de la región acude a la cabecera municipal, pues se ha convocado a un grupo de aproximadamente cuarenta jóvenes para que conozcan la propuesta de la Plataforma. El municipio donde se encuentran se dedica a la fruticultura (huertas manzaneras), y gran parte de la población trabaja por jornales en actividades como el desahije y la pizca de la manzana, así como en su procesamiento a través de empacadoras locales.

La comunidad y el municipio es aquejada por el narcotráfico, la venta de drogas como marihuana y cocaína, la disputa del territorio y enfrentamientos armados entre grupos del crimen organizado. Frecuentemente, se recluta a la juventud para ejercer actividades de sicarios, narcomenudistas o "halcones" (vigilancia del territorio). Se presentan delitos como homicidios, robos, narcomenudeo y privaciones ilegales de la libertad ${ }^{73}$.

El municipio no cuenta con mucha infraestructura educativa y no hay mucha inversión privada en el sector industrial (maquiladoras), lo que expulsa a los jóvenes que emigran hacia Estados Unidos en busca del "sueño americano" y algunos otros a

73 Carolina Macías, supra, nota 4. 
ciudades como Chihuahua (capital), Ciudad Juárez o Ciudad Cuauhtémoc para continuar con sus estudios en un nivel superior y para encontrar fuentes de empleo.

El colectivo está conformado por cuatro jóvenes que entran en el rango de edad y otro miembro que rebasa el rango; sin embargo, cabe mencionar que se ha identificado que los grupos heterogéneos presentan mayores posibilidades de permanencia. En cuanto a los resultados en la herramienta de focalización, tres de ellos presentan nivel alto y uno tiene nivel crítico de riesgo.

Inicialmente, los jóvenes que integran el colectivo mencionan que no tenían mucha fe en el proyecto y que les costaba cumplir los compromisos asumidos, pero con el tiempo se fueron interesando y encontrando razones para permanecer. Los jóvenes no tenían una relación de amistad previa al proceso, es a partir del trabajo con énfasis en la dimensión social que el equipo se va conformando, se van relacionando y conociendo hasta encontrar los puntos comunes que los llevaron a definir cuál sería su idea de negocio. La primera idea que planteaba el colectivo era producir carne de conejo, pero después de un estudio de mercado identificaron que hay una necesidad insatisfecha que sugería que había mejores oportunidades si se dedicaban a la producción de huevo ranchero, ya que en el mercado solo hay huevo industrializado que está cargado de hormonas, por lo que la comunidad lo percibe como alimento poco saludable $e^{74}$.

Los colectivos de la Plataforma no cuentan con un capital semilla de inicio, pues se contempla que no sea el dinero lo que atraiga a las juventudes a involucrarse en el trabajo de la Plataforma. Esto se traduce en un reto para el propio colectivo, pues son ellos mismos quienes tienen que gestionar los recursos para poder llevar a cabo su emprendimiento. Las figuras del orientador y del dinamizador se vuelven claves, pues si bien los jóvenes son quienes deben buscar los medios, el orientador y el dinamizador son quienes construyen las relaciones a nivel institucional para facilitar las gestiones por parte del colectivo.

Como en el caso anterior, los jóvenes reportan que a partir de entender y empezar a vivir los principios y valores de la Economía Social, se van consolidando entre ellos; se conocen en los mejores y peores momentos hasta construir una relación de tanta confianza que se asumen como una familia, y las necesidades del emprendimiento las colectivizan porque en su narrativa ya está instalado que juntos logran lo que solos no.

La seguridad de los jóvenes se ha visto fortalecida gracias a la iniciativa del orientador para promover su participación en entrevistas radiales, los ha llevado a foros donde comparten su experiencia y los ha motivado a ser activos en la

74 Id. 
promoción de sus avances; esto ha logrado empoderarlos y hoy se perciben como agentes de cambio.

Los jóvenes inician su actividad económica aportando cada uno dinero y trabajo. Logran comprar 123 gallinas "de segunda mano" y construyen ellos mismos una pequeña nave que les permite comenzar con su producción, la misma que hoy les genera los ingresos necesarios para mantener el espacio y a las gallinas.

Este colectivo ha tenido la peculiaridad de tener diversos apoyos del sector público a través de la Secretaría de Desarrollo Social del estado, que les presentó alternativas para seguir con las capacitaciones técnicas y los apoyó con la gestión de unas becas del programa federal "Jóvenes Construyendo el Futuro" (actualmente están esperando el recurso que ya les ha sido asignado para apoyar su actividad, por un monto de 300000 pesos).

Por su parte, la Secretaría de Innovación y Desarrollo Económico los apoyó con la constitución legal de la cooperativa, condonándoles todos los gastos del trámite legal.

Por otro lado, el sector académico también ha apoyado el fortalecimiento y la consolidación del colectivo gracias a la impartición de formaciones especializadas a través de aliados como el Tecnológico de Cuauhtémoc y el Icatech. El sector privado ha contribuido desde las cámaras empresariales y de comercio con algunas formaciones y mentorías.

Lo más relevante del colectivo, además de esta red de apoyo, es que temprano en el proceso de incubación se dieron cuenta de que su círculo de amistades previo no les dejaba nada positivo y que por el contrario solía meterlos en problemas. A partir del emprendimiento, comienzan a sentir la necesidad de prepararse, por lo que se reúnen a investigar y a ver tutoriales en el tiempo adicional al que tienen con el orientador en las sesiones de incubación y acompañamiento.

Los jóvenes se han vuelto auténticos promotores de la Economía Social y el emprendedurismo: "Antes pensábamos que no íbamos a salir de pobres porque éramos simples jornaleros, pero hoy hasta nos sentimos diferentes".

\section{OBSERVACIONES}

Sería apresurado afirmar que a dos años de la implementación del programa se ha logrado validar la hipótesis planteada. Se observa que el tema del ingreso y el acceso al trabajo no es la primera necesidad que el joven, al participar en un proceso de emprendimiento, logra cumplir; por el contrario, este paso es más tardío. Sin embargo, se encuentran algunas evidencias de que, en estas circunstancias, la empresa se 
vuelve un medio para que el joven desarrolle otro tipo de condiciones que lo fortalecen; por ejemplo, las habilidades obtenidas desde la dimensión social adquieren un sentido profundo.

Desde el aporte de la dimensión social, se observa un incremento en la autoestima de los jóvenes, en el planteamiento de metas y objetivos, y en el desarrollo de un proyecto de vida, que si bien se construye desde lo individual, en el paso por la empresa se pone en colectivo. Al mismo tiempo, el acompañamiento les aporta el desarrollo de habilidades de comunicación y entre ellas la escucha es fundamental para entender las necesidades de los otros y generar un proceso de empatía.

La metodología inspira un acercamiento del joven con su comunidad. Es a través de la gamificación que se ha promovido el liderazgo de los jóvenes en sus colonias, quienes han participado en acciones comunitarias que les permiten romper con los estigmas sociales en los que normalmente los tienen catalogados.

Se observa, en algunos casos, un proceso de autorreflexión en el que los jóvenes empiezan a tomar decisiones más meditadas con respecto al consumo de sustancias adictivas. Cabe mencionar en este punto que es fundamental contar con aliados que ayuden en procesos efectivos de rehabilitación

La participación del joven en un proceso colectivo le fortalece el desarrollo de compromisos y responsabilidades, siendo el mismo colectivo quien regula el proceso. Hay un proceso de empatía que pasa por el autorreconocimiento y que detona que el colectivo se asuma, incluso, como un agente de cambio.

Por otro lado, la ruta del emprendimiento debe mantenerse en constante adaptación a las realidades de los territorios, a fin de incorporar la experiencia de los orientadores al proceso formativo:

- La población objetivo demanda que el orientador tenga un perfil muy definido que no siempre se encuentra en todos los territorios, sobre todo cuando se trabajan los rubros de habilidades socioemocionales.

- En relación con los acompañamientos, un reto importante es mantener el enfoque e interés de los jóvenes en el emprendimiento, ya que la necesidad de un ingreso económico inmediato es un factor de deserción, pues no se resuelve en corto tiempo.

- Mediante la aplicación de algunos instrumentos de evaluación, participantes manifiestan cambios en la actitud en los jóvenes en lo personal: están entusiasmados, abiertos a socializar con otras personas y con otros emprendimientos; más centrados en su persona, con autoconocimiento y seguridad en sí mismos; y están más enfocados y comprometidos con 
sus objetivos, son más disciplinados y tienen una visión más clara de cómo hacer las cosas.

- Los jóvenes que participan en procesos similares y presentan algunos de los cambios mencionados en el párrafo anterior funcionan como jóvenes tractores de otros, en el mismo contexto, motivándolos a impulsar también cambios similares.

- Se presentan algunas alteraciones en la percepción de la comunidad y en el contexto inmediato sobre los jóvenes al verlos participando en otro tipo de actividades. Por otro lado, se fortalece el apoyo y la confianza hacia estos jóvenes de parte de sus familiares y amigos, pues se reconocen algunos sentimientos de gratitud y orgullo hacia ellos.

\section{REFERENCIAS}

Agencia de Estados Unidos para el Desarrollo Internacional (USAID). ¿QUÉ FUNCIONA PARA PREVENIR Y REDUCIR LA VIOLENCIA JUVENIL? REVISIÓN SISTEMÁTICA DE LA EVIDENCIA SOBRE PREVENCIÓN Y REDUCCIÓN DE LA VIOLENCIA JUVENIL, CON UN ANÁLISIS APLICADO AL CONTEXTO MEXICANO. MéXiCO D.F.: USAID. (2018).

Agencia de Estados Unidos para el Desarrollo Internacional (USAID). PREVENCIÓN DE LA VIOLENCIA JUVENIL: RETOS Y OPORTUNIDADES EN MÉXICO Y AMÉRICA LATINA. MéXico D.F.: USAID. (2018).

Agencia de Estados Unidos para el Desarrollo Internacional (USAID). THRUSTING SUSTAINABLE Violence and Crime Prevention Approaches in Mexico. México D.F.: USAID. (2018).

Asamblea General de Naciones Unidas. DIRECTRICES DE RIAD. ONU. (1990).

Banco Mundial. La VIOLENCIA JUVENIL EN MÉxICO. RePORTE dE LA SITUACIÓN, EL MARCO LEGAL Y LOS PROGRAMAS GUBERnAMENTALES. Washington D.C.: Banco Mundial. (2012).

Carolina Macías. Incubación de empresas juveniles de Economía Social, modelo para prevención de violencia y construcción de seguridad ciudadana juvenil Caso: Grupo BSCH. REVISTA IBERO 67. Abril-mayo 2020.

David Sánchez-Teruel. Factores de riesgo y protección ante la delincuencia en menores y jóvenes. RES: ReVISTA de EduCACIón SOCIAL 15. Julio 2012. Pág. 1-12. 
Francisco Castellanos García. CONSTRUYENDO MODELOS DE INTERVENCIÓN CON JÓvENES. México D.F.: Programa para la Convivencia Ciudadana USAID. (2015).

Franz Vanderschuere, et al. GUÍA PARA LA PREVENCIÓN LOCAL HACIA POLÍTICAS DE COHESIÓN SOCIAL Y SEGURIDAD CIUDADANA. Santiago: Programa de las Naciones Unidas para los Asentamientos Humanos (onu Hábitat); Universidad Alberto Hurtado de Chile. (2009).

Fundación Carlos Slim. Diplomado PREVEnción DE LAS VIOLENCIAS Y FORTALECIMIENTO DE LA SEGURIDAD CIUDADANA. México D.F.: Fundación Carlos Slim. (2019).

Fundación Carlos Slim. JustıCIA. s. f. Disponible en https://fundacioncarlosslim.org/justicia/

ibero Puebla. Metodología Para el acompañamiento e incubación de empresas de EConomía SocIaL. Puebla: Universidad Iberoamericana Puebla. (2017).

Interpeace Regional Office for Latin America. 12 ESTRATEGIAS PARA PREVENIR LA VIOLENCIA ASOCIADA CON LA ADOLESCENCIA Y LA JUVENTUD. Ciudad de Guatemala: Interpeace Regional Office for Latin America. (2010).

Juntos para la Prevención de la Violencia (JPV). HeRramienta yTt: HeRRAmIENTA de FocalizAción DE Jóvenes en Riesgo. Manual de usuario. México D.F.: USAID. (2017).

Laboratorio de Innovación Económica y Social (LAINES). REPORTE ANUAL PCSCJM 2018. Puebla: LAINES. (2018).

Laboratorio de Innovación Económica y Social (LAINES). REPORTE ANUAL PCSCJM 2019. Puebla: LAINES. (2019).

Nadia Eslinda Castillo Romero. Los movimientos de Economía Socialy contrucción de paz: una introducción. Coord. Nadia Eslinda Castillo Romero. EConomía socIAL EN CONTEXTOS DE VIOLENCIA: MÉxico y Colombia. Puebla: Universidad Iberoamericana Puebla; Universidad Cooperativa de Colombia. (2018).

Nadia Eslinda Castillo Romero, Coord. EConomía social EN CONTEXTOS DE VIOLENCIA: MÉxICO y Colombia. Puebla: Universidad Iberoamericana Puebla; Universidad Cooperativa de Colombia. (2018).

ONU Mujeres. Marco eCOLóGico. 2013. Disponible en https://www.endvawnow.org/es/articles/1509-marco-ecolgico.html 
Organización Mundial de la Salud (OMS). LA PREVENCIÓN DE LA VIOLENCIA JUVENIL: PANORAMA GENERAL DE LA EVIDENCIA. Washington D.C.: OPS. (2016).

Percy Calderón Concha. Teoría de conflictos de Johan Galtung. Revista PAZ y Conflictos 2. 2009. Pág. 60-81.

Programa de las Naciones Unidas para el Desarrollo (PNUD). INFORME SOBRE DESARROLLO HUMANO 1994. México D.F.: Fondo de Cultura Económica (1994).

Programa de las Naciones Unidas para el Desarrollo (PNUD). INFORME REGIONAL DE DESARROLLO HumANO 2013-2014. SEgURIDAd CIUdAdANA CON ROSTRO HUMANO: DIAGNÓSTICO Y PROPUESTAS PARA AMÉRICA LATINA. Nueva York: PNUD. (2013).

Programa de las Naciones Unidas para el Desarrollo (PNUD). APOYO DEL PNUD A LA IMPLEMENTACIÓN DEL OBJETIVO DE DESARROLLO SOSTENIBLE. REDUCIR LA DESIGUALDAD EN Y ENTRE LOS PAíSES. Nueva York: PNUD. (2016).

Programa de las Naciones Unidas para el Desarrollo (PNUD). EMPODÉRATE: JóVENES CREARÁN EMPRESAS SOCIALES EN COMUNIDADES VULNERABLES. Noticias. 8 de febrero de 2019. Disponible en www.mx.undp.org/content/mexico/es/home/presscenter/articles/2019/02/empoderate---jovenes-crearan-empresas-sociales-en-comunidades-vu.html

Tani Adams. LA VIOLENCIA CRÓNICA Y SU REPRODUCCIÓN: TENDENCIAS PERVERSAS EN LAS RELACIONES SOCIALES, LA CIUDAdANíA Y LA DEMOCRACIA EN AmÉRICA LATINA. Wilson Center. (2012).

The Institute for Economics and Peace (IEP). ÍNDICE DE PAZ MÉXICO 2018: PANORAMA DEL NIVEL DE PAZ EN MÉxıco. México D.F.: IEP. (2018).

The Institute for Economics and Peace (IEP). ÍNDICE DE PAZ MÉXICO 2019: IDENTIFICAR Y MEDIR LOS FACTORES QUE IMPULSAN LA PAZ. México D.F.: IEP. (2019).

Ximena Tocornal. Apoyando La prevención en AmÉRICA LATInA. Santiago: Centro de Estudios en Seguridad Ciudadana. (2004). 